\title{
Caspase selective reagents for diagnosing apoptotic mechanisms
}

\author{
Marcin Poreba ${ }^{1,2} \cdot$ Katarzyna Groborz $^{2} \cdot$ Mario Navarro $^{1} \cdot$ Scott J. Snipas ${ }^{1} \cdot{\text { Marcin } \text { Drag }^{2} \cdot \text { Guy S. Salvesen }}^{1}$
}

Received: 7 November 2017 / Revised: 30 January 2018 / Accepted: 14 March 2018 / Published online: 10 May 2018

(c) ADMC Associazione Differenziamento e Morte Cellulare 2018

\begin{abstract}
Apical caspases initiate and effector caspases execute apoptosis. Reagents that can distinguish between caspases, particularly apical caspases-8, 9, and 10 are scarce and generally nonspecific. Based upon a previously described large-scale screen of peptide-based caspase substrates termed HyCoSuL, we sought to develop reagents to distinguish between apical caspases in order to reveal their function in apoptotic cell death paradigms. To this end, we selected tetrapeptide-based sequences that deliver optimal substrate selectivity and converted them to inhibitors equipped with a detectable tag (activity-based probesABPs). We demonstrate a strong relationship between substrate kinetics and ABP kinetics. To evaluate the utility of selective substrates and ABPs, we examined distinct apoptosis pathways in Jurkat T lymphocyte and MDA-MB-231 breast cancer lines triggered to undergo cell death via extrinsic or intrinsic apoptosis. We report the first highly selective substrate appropriate for quantitation of caspase-8 activity during apoptosis. Converting substrates to ABPs promoted loss-of-activity and selectivity, thus we could not define a single ABP capable of detecting individual apical caspases in complex mixtures. To overcome this, we developed a panel strategy utilizing several caspase-selective ABPs to interrogate apoptosis, revealing the first chemistry-based approach to uncover the participation of caspase-8, but not caspase- 9 or -10 in TRAIL-induced extrinsic apoptosis. We propose that using select panels of ABPs can provide information regarding caspase-8 apoptotic signaling more faithfully than can single, generally nonspecific reagents.
\end{abstract}

\section{Introduction}

Apoptosis is a naturally occurring, tightly regulated process through which damaged or unwanted cells are removed from an organism to maintain cellular homeostasis [1].

\section{Edited by V Dixit}

Electronic supplementary material The online version of this article (https://doi.org/10.1038/s41418-018-0110-y) contains supplementary material, which is available to authorized users.

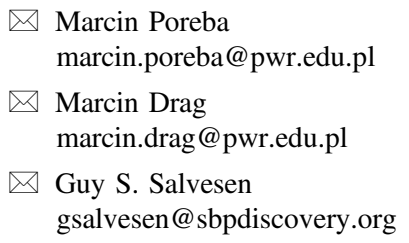

1 NCI Designated Cancer Center, Sanford Burnham Prebys Medical Discovery Institute, 10901 North Torrey Pines Road, La Jolla, CA 92037, USA

2 Department of Bioorganic Chemistry, Faculty of Chemistry, Wroclaw University of Science and Technology, Wyb. Wyspianskiego 27, 50-370 Wroclaw, Poland
Apoptosis is also a desired outcome of cancer therapies including irradiation, chemo-, gene-, and immune-therapies designed to eliminate the transformed cells by cell suicide [2]. Apoptosis is orchestrated by a family of proteases called caspases, which are synthesized as inactive zymogens and activated by processing or by recruitment of molecular platforms that promote their dimerization (Fig. 1a) [3]. Generally, apoptotic caspases are classified as apical (caspase-8, -9, and -10) or effector (-3, -6, and -7) (Fig. 1a) [4]. Depending on the environment, caspase- 2 can act as either, or even in non-apoptotic role [5]. Once activated, caspases cleave a set of protein substrates to trigger phenotypes modulated by altered expression and/or activity of pro-apoptotic and anti-apoptotic proteins that respectively support or block cell death $[6,7]$. The biochemical hallmarks of apoptosis are DNA fragmentation and membrane blebbing, as well as cell shrinkage, resulting in the formation of apoptotic bodies engulfed by surrounding cells, a process thought to be immunologically silent [8]. Intriguingly, a second branch of the caspase family, encompassing caspases 1,4 , and 5 in humans, executes an entirely different form of cell death, a highly inflammatory activity known as pyroptosis, which triggers the release of inflammatory cytokines from phagocytic cells [9]. 
A

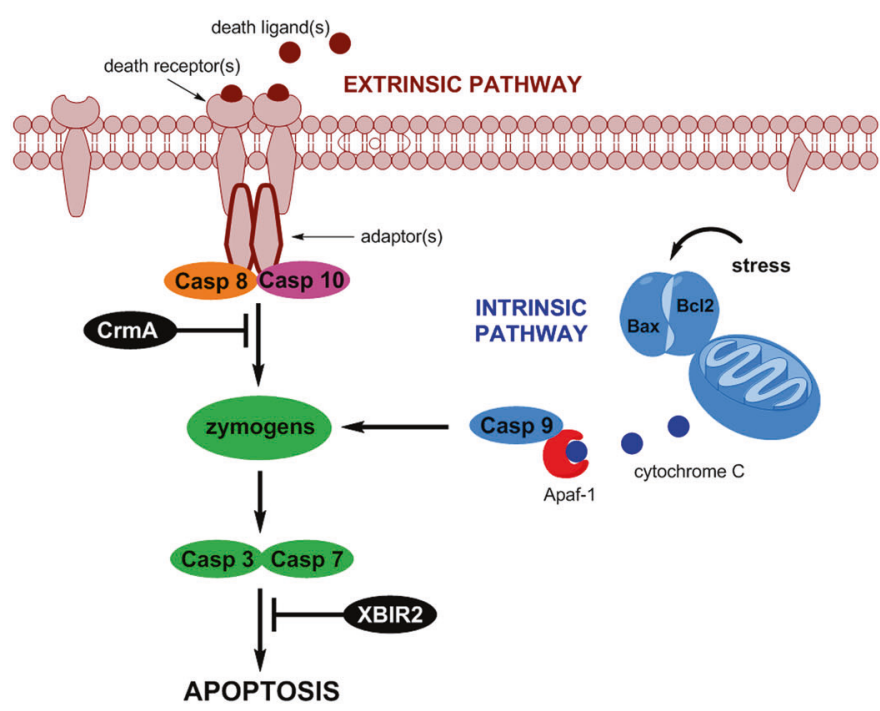

B

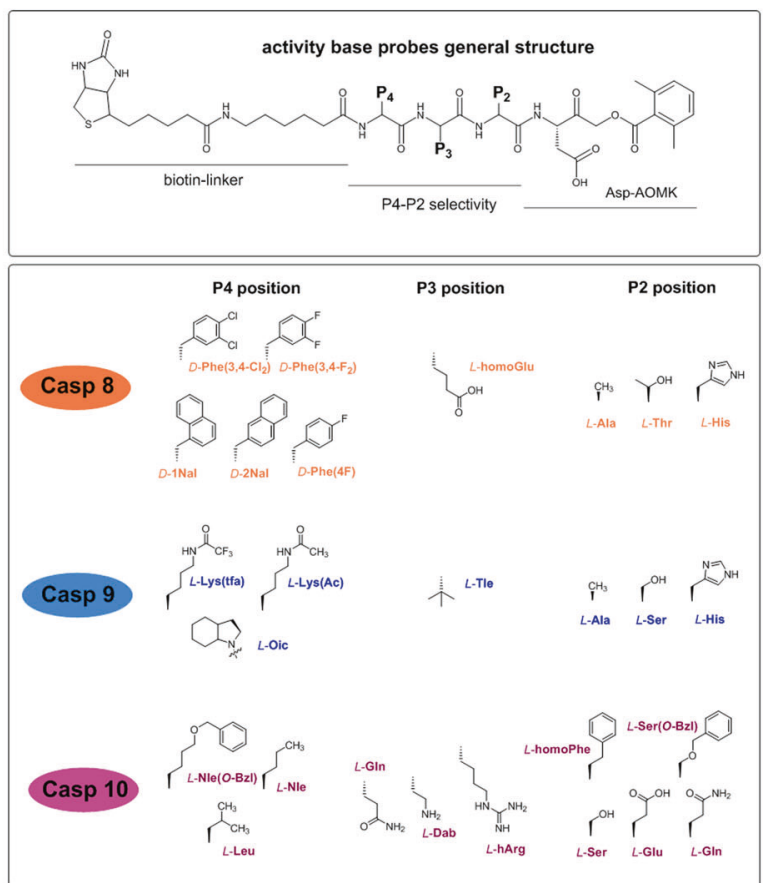

Fig. 1 ABPs used for caspase analysis. a Two initiation pathways triggered by separate events converge at a common point to execute apoptosis in mammals. The extrinsic apoptosis pathway is triggered by extracellular ligation of death receptors, resulting in receptor clustering, adapter recruitment, and activation of the apical protease caspase8 and possibly its close paralog caspase-10 (active enzymes are shown in orange/pink ovals-reviewed in ref. [57]). The intrinsic pathway responds primarily to cellular stress and some neurodevelopmental cues, with mitochondria acting as important integrators. Pro-apoptotic and anti-apoptotic members of the Bcl2 family (Bax and Bcl2 serve as examples) regulate the lethal stress-response threshold (reviewed in [58]). Activation of the apical caspases- $8,-9$, and -10 occurs when they

Since their active site is conserved, caspases display overlapping substrate specificity [4, 10]. Although they have distinct substrate repertoires in vivo, it has been difficult to generate diagnostic or therapeutic small molecules selective for individual caspases [11, 12]. Previously, we performed a large-scale analysis to obtain highly selective peptide-based substrates capable of distinguishing between closely related apoptotic caspases, using a process we developed called HyCoSuL (Hybrid Combinatorial Substrate Library) screening [13, 14]. The substrates we developed cannot be used to visualize specific caspase activation in complex biological material, as the product diffuses away. Accordingly, we set out to convert the caspase HyCoSuL-derived substrates into probes that would (1) remain bound to the active form of target caspases and (2) serve to inhibit individual caspases in complex samples. The general method of detecting specific active enzymes, including caspases, by activitybased profiling has been described in detail previously [15-19]. are driven into an active conformation by their activation platformsthe DISC (death-inducing signaling complex) or the Apaf-1 apoptosome $[59,60]$. Both pathways activate the effector proteases, caspases3 and -7. Relevant to the extrinsic pathway, signals from several receptors, in response to cognate ligands, converge to activate caspases- 8 and -10 (reviewed in ref. [61]). CrmA is a viral inhibitor of caspase- 8 and XBIR2 is the second BIR domain of XIAP (X-linked inhibitor of apoptosis protein), highly selective for of caspases-3 and -7 [62-64]. b General structure of amino acids selected for synthesis of ABPs targeting the apoptotic apical caspases-8, -9, and -10. In each case, the P1 position was fixed as Asp

Caspases must be catalytically active to kill a cell; therefore, we reasoned that a set of selective activity-based probes (ABPs) might be helpful to better define individual caspases functioning in apoptotic processes. The most widely used reagent to inhibit caspases is cell-permeable carbobenzoxy-Val-Ala-Asp(OMe)-fluoromethyl ketone (Z$\mathrm{VAD}(\mathrm{OMe})-\mathrm{FMK})$ [11, 20]. However, Z-VAD(OMe)FMK has a broad activity spectrum and also inhibits cysteine cathepsins, and thus is not a useful tool to block individual caspases. Even the substrates and the probes synthesized based on allegedly selective caspase sequences (DEVD, LEHD, or IETD) lack specificity and can lead to erroneous conclusions [21-23]. We predicted that use of a wide set of unnatural amino acids in peptide structures, based on prior HyCoSuL screens, that would allow us to synthesize probes more selective than those containing natural amino acids only. Accordingly, we synthesized probes designed to exhibit the greatest selectivity in differentiating apical caspases- $8,-9$, and -10 from each other and from the primary effector caspase- 3 . We then used them 
to monitor the kinetics of apoptosis initiation in Jurkat $\mathrm{T}$ cells induced to undergo apoptosis by TRAIL (TNFrelated apoptosis-inducing ligand) or etoposide and to define the functions of individual caspases in that activity. Specifically, we sought to differentiate the participation of apical caspases of the extrinsic apoptosis pathway, namely, caspases- 8 and -10 from the activity of caspase-9, an apical caspase of the intrinsic apoptosis pathway.

\section{Results}

\section{Conversion of substrates to activity-based probes}

To determine whether we could convert substrate sequences into probes targeting individual caspases, we designed and synthesized selective ABPs to covalently and irreversibly bind (and label) only active forms of caspases, to provide tools to discriminate the functions of specific caspases during apoptosis. Since apoptotic caspases display overlapping substrate specificity and cannot be distinguished using peptides constructed of natural amino acids, we used data from our previously published HyCoSuL approach, in which we assessed the caspase preferences toward substrates comprised of unnatural amino acids [13, 14]. The approach yielded several tetrapeptide sequences displaying high selectivity for individual caspases. Here, we employed those sequences to synthesize 38 different ABPs representing five classes: (1) four broad-spectrum probes for all the 5 caspases, (2) one probe selective for the closely related caspases-3 and -7 , (3) 8 caspase- 9 selective probes, (4) 11 caspase- 8 selective probes, and (5) 14 caspase-10 selective probes. These sequences were optimized for selectivity and thus their catalytic activity was lower than the optimal substrates for each caspase. As a scaffold for ABPs, we employed biotin-ahx-(P5)-P4-P3-P2-P1-AOMK (Fig. 1b), as biotin is bound by streptavidin, providing means to capture active caspases from lysates of apoptotic cells. To separate the biotin moiety from the caspase active site, we incorporated a 6-aminohexanoic (ahx) spacer into the ABP. As an electrophilic covalently reacting reagent (warhead), we utilized acyloxymethyl ketone (AOMK) [24]. Critical for these ABPs is the P4-P2 sequence primarily built of unnatural amino acids, a feature that significantly enhances the target selectively (Fig. 1b). For caspase-8, we selected hydrophobic, bulky $D$-amino acids at the P4 position, homoglutamic acid at P3, and Ala, Thr, or His at P2 (probes MP-8.01..8.11). For caspase-10 selective ABPs, we used aliphatic amino acids at P4 (Leu, hLeu-homoLeucine, Nle —norLeucine, or $\mathrm{Nle}(O$-Bzl)_6-benzyloxynoreLeucine), basic amino acids Dab (aminohomoAlanine) or hArg (homoArginine) or the acidic Glu at the P3 position, and a variety of structures at $\mathrm{P} 2$ (hPhe-homoPhenylalanine, Ser
$(O-\mathrm{Bzl})$ - serine benzyl ether, Gln, Glu, or Ser) (probes $M P$ 10.01...10.14). Finally, caspase-9 ABPs contained Oic (octahydroindole-2-carboxylic acid), Lys(tfa) (trifluoroacetylLysine), or Lys(Ac) (acetylLysine) at P4, tertleucine at P3, and Ala, Ser, or His at P2 (probes MP-9.01... 9.07) (Fig. 1b; Table S1). To increase selectivity of caspase9 probes over caspase-3, we included an additional amino acid (proline) at P5 (Table S1). We also developed an effector caspase ABP (MP-3.01) that targeted caspases-3 and 7 , and was poorly reactive with apical caspases, as well as four broad-spectrum probes (DEVD, IETD, LEHD, and LQnD) (Table S1).

\section{Catalytic parameters of activity-based probes correlate well with substrates}

To test ABP selectivity, we measured their inhibition potency across seven recombinant apoptotic caspases: caspases-2, -3, -6, -7, -8, -9, and -10, and also two ubiquitously expressed cysteine cathepsins ( $\mathrm{L}$ and $\mathrm{B}$ ), which are also known to be inhibited by AOMK-based peptides (Table S2). Cathepsins were very poorly inhibited, although trace labeling was observed for some probes (Figure S1). Almost all ABPs tested displayed a classic irreversible mode of inhibition of caspase-2, -3, -6, -7, and -10, fitting a general irreversible pseudo first-order equation with no observable reversible equilibrium, enabling us to calculate second-order rates $\left(k_{\text {obs }} / I\right)$ (Fig. $2 \mathrm{a}$; Table S2). Interestingly, however, for caspase-8 and -9 , only some probes (DEVD, IETD, LEHD, and LQnD) showed fully irreversible behavior (Fig. 2a; Table S2). Other probes displayed fastbinding reversible kinetics, while others displayed bimodal inhibition kinetics. Thus, we calculated $K_{\mathrm{I}}$ (equilibrium constant) for the fast-binding reversible probes, and both $k_{\text {obs }} / I$ (rates of inhibition) and $K_{\mathrm{I}}$ parameters for the bimodal inhibitors (Fig. 2b,c; Table S2, S3). This different kinetic behavior of various ABPs is in line with the previous observation that not all of the AOMK-based peptides are irreversible inhibitors, and the mode of inhibition can also be dictated by the inhibitor peptide sequence [25]. Regardless of inhibitory mode (reversible or irreversible), our MP-8.0x, MP-9.0x, and MP-10.xx probes displayed high selectivity across caspases tested (Fig. 3a; Table S2, S3), and they are the most selective small-molecule ABPs for apical caspases reported to date [11].

Since we designed probes to capture and detect activity of individual caspases in apoptotic cells, we asked whether all probes, including reversible ones, formed durable adducts with target enzymes, as assessed by adduct stability under denaturing conditions. To do so, we incubated $50 \mathrm{nM}$ active site-titrated caspase with $100 \mathrm{nM}$ probe for $30 \mathrm{~min}$, and then performed SDS-PAGE and Western blotting to detect biotin-tagged probes with fluorescent streptavidin 

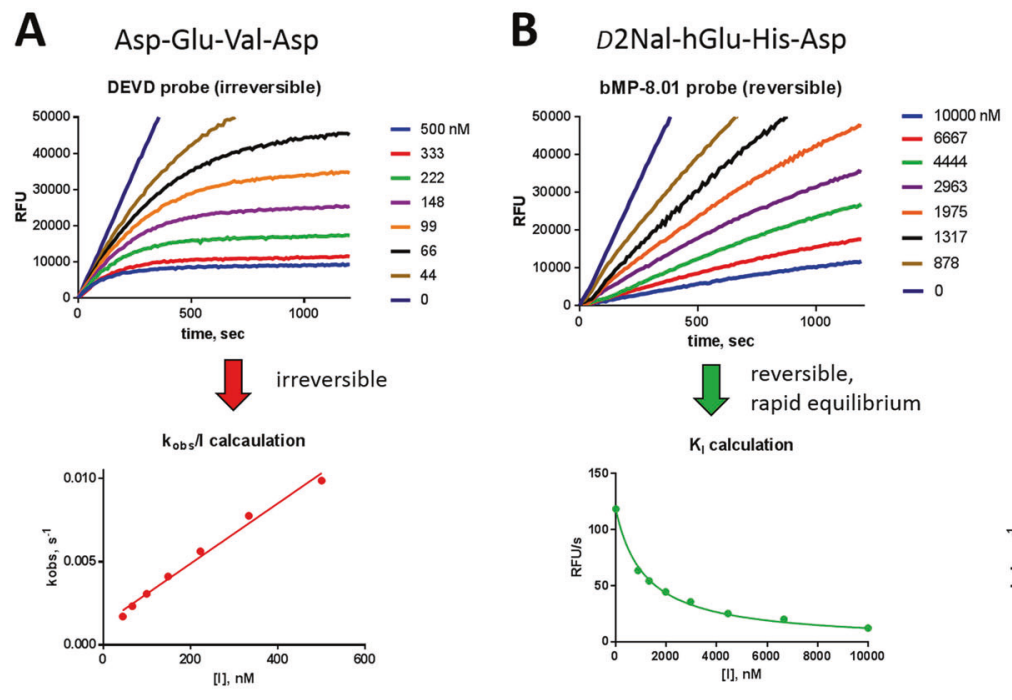

C D2Nal-hGlu-Thr-Asp
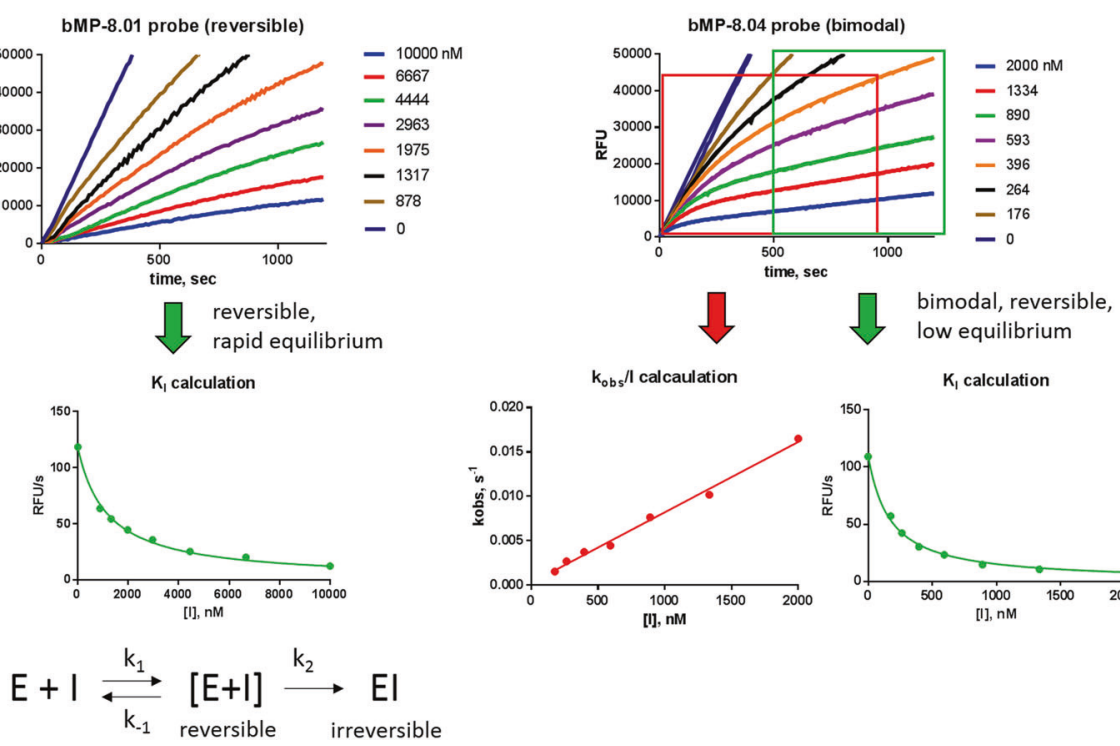

$\mathrm{k}_{\mathrm{obs}} / \mathrm{l}$ calcaulation

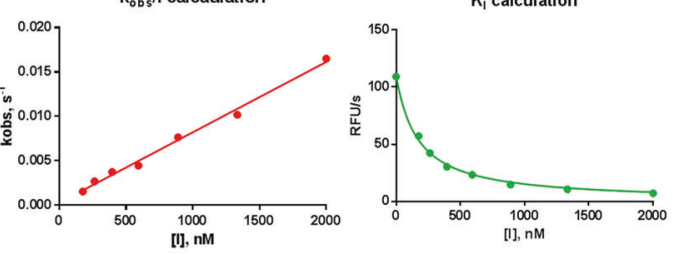

reversible

Fig. 2 Distinct mechanisms of caspase-8 inhibition by AOMK ABPs. Progress curves show that inhibition is irreversible (a), reversible (b), or bimodal (c). In b,c, the switch between reversible and bimodal

inhibition occurs following exchange of one amino acid (His $\rightarrow$ Thr) in the $\mathrm{P} 2$ position of the AOMK-activity-based probe

(Fig. 3b). Using the $k_{\mathrm{obs}} / I$ data, we calculated that $100 \mathrm{nM}$ of broad-spectrum probe (biotin-ahx-LEHD-AOMK) is sufficient to inhibit all tested caspases over the period of $30 \mathrm{~min}$ (see Scheme S1 for details). As expected, the irreversible probes efficiently labeled the caspases; however, unexpectedly, reversible probes were also stable after boiling in SDS. More importantly, some probes appeared highly selective, as they robustly labeled the target caspase and either poorly labeled or did not label others (Fig. 3b). For example, caspase-9 selective probes (MP-9.01, -9.02, and 9.03) displayed minimal cross-reactivity with casapase-10, caspase-8 selective probes (MP-8.01, -8.02, and 8.03) showed some minor cross-reactivity with only caspase-3, and finally among caspase- 10 ABPs series, two probes (MP-10.07 and -10.09) were very selective across all tested caspase. These observations demonstrate that out initial prediction, that caspase-selective substrate sequences can be converted to selective ABPs, is largely valid.

Since the ABPs were based on caspase substrate specificity profiling, we predicted a positive correlation between the second-order rate of inhibition $\left(k_{\mathrm{obs}} / I\right)$ and second-order rate of catalytic efficiency $\left(k_{\text {cat }} / K_{\mathrm{M}}\right)$ of substrates harboring the 7-amino-4-carbamoylmethylcoumarin (ACC) fluorophore, containing identical P4-P1 sequences. In other words, substrates with high turnover kinetic constants serve as good scaffolds for ageneration of potent inhibitors, by replacing the ACC fluorophore with an electrophilic warhead (i.e., AOMK), however, as shown previously, such inhibitors lose some selectivity [26]. To test this, we synthesized 19 peptidyl fluorogenic substrates of the formula of Ac-peptide-ACC and measured their kinetic parameters against caspases- $2,-3,-6,-7,-8,-9$, and -10 (Fig. 4; Table S4, S5). This analysis revealed that caspases-3, -6, -7, -8, -9, and -10 displayed strong positive correlations between substrate $k_{\mathrm{cat}} / K_{\mathrm{M}}$ and $\mathrm{ABP} k_{\mathrm{obs}} / I$ values (Fig. 4b,c). Caspase-2 and -6 showed minimal catalytic activity against most of the ACC substrates, thus the correlation was not possible. We did not attempt to correlate the substrate catalytic parameters with $K_{\mathrm{i}}$, since the dimensions are not comparable. Substrates with His at P2 were rapidly hydrolyzed, but probes or inhibitors with P2 His were less potent than those with Ala or Thr at P2, at least in terms of $K_{\mathrm{i}}$ (Fig. $\left.4 \mathrm{~d}, \mathrm{e}\right)$. We hypothesize that His at P2 may promote substrate hydrolysis and caspase inhibition via different mechanisms. In support of this hypothesis, we found that caspase- 8 and caspase- 9 probes with P2 His displayed reversible inhibition, while probes with $\mathrm{Thr}$ or Ala at P2 demonstrated bimodal inhibition. Seeking an explanation for the differential inhibition, we note that it has previously been demonstrated (using caspase-1) that the catalytic His residue stabilizes the AOMK leaving group, thus promoting the formation of irreversible inhibitor-caspase complex [25]. However, when His is also present in inhibitor/ABP structures at the $\mathrm{P} 2$ position, we speculate that these two positively charged His groups (assayed at $\mathrm{pH}$ 7.2) may repel each other and prevent irreversible inhibition. Such His stabilization is not important for substrate hydrolysis, thus peptides with His at $\mathrm{P} 2$ are efficiently turned over by caspase- 8 and -9 (Table S5). 


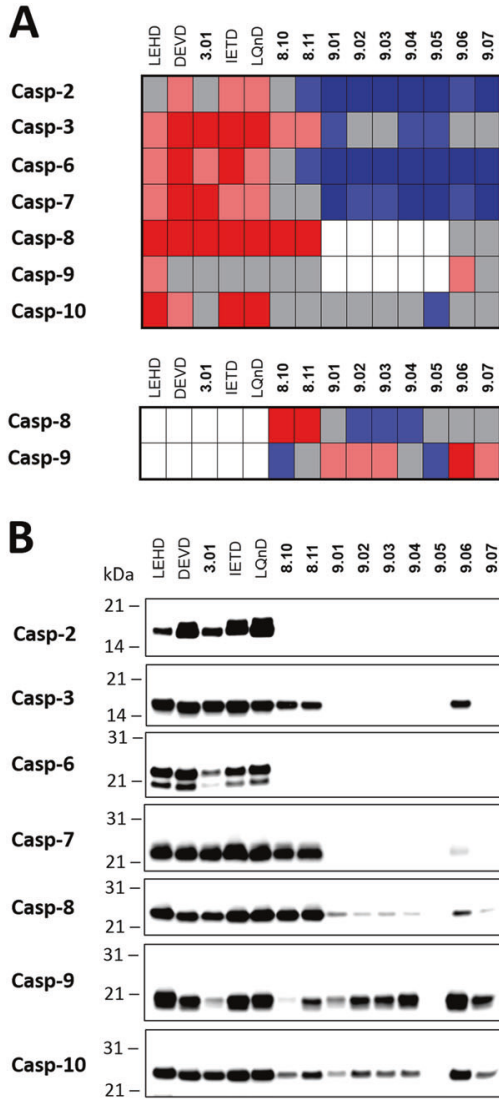

Fig. $3 \mathrm{ABP}$ selectivity toward five human apoptotic caspases. a Kinetic parameters $\left(k_{\mathrm{obs}} / I\right.$ and $\left.K_{\mathrm{I}}\right)$ of ABPs for caspases displayed as heatmaps. All ABPs were irreversible for caspase-2, -3, -6, -7, and -10. Caspase- 8 and -9 displayed either irreversible or reversible inhibition, depending on the ABP tested. b ABP selectivity tested by labeling of recombinant caspases. Probes $(100 \mathrm{nM})$ were incubated with active

\section{Analysis of the extrinsic apoptosis pathway using substrates and activity-based probes}

Based on our initial analysis of compounds displaying high selectivity toward individual caspases, we concluded that it would be sensible to avoid His in P2. We next asked whether a kinetically diverse set of substrates and probes can be used to dissect the role of individual caspases in apoptosis process. To do so, we focused on the highly investigated extrinsic pathway initiated by TRAIL [27, 28] and selected Jurkat $\mathrm{T}$ cells as a model system, as these cells readily undergo apoptosis following TRAIL stimulation (Fig. 5a; Figure S2) [29, 30]. We treated proliferating Jurkat $\mathrm{T}$ cells with recombinant TRAIL, and then monitored caspase and PARP cleavage at various time points (Fig. 5b). We found that within an hour of TRAIL stimulation, caspase- 8 is processed from $\mathrm{p} 55$ into $\mathrm{p} 43 / \mathrm{p} 12$ forms, consistent with autolytic maturation. We could not detect the large subunit devoid of the pro-domains (p18), possibly because the pro-domains had not been released during the course of our assay, or because the antibody used had poor
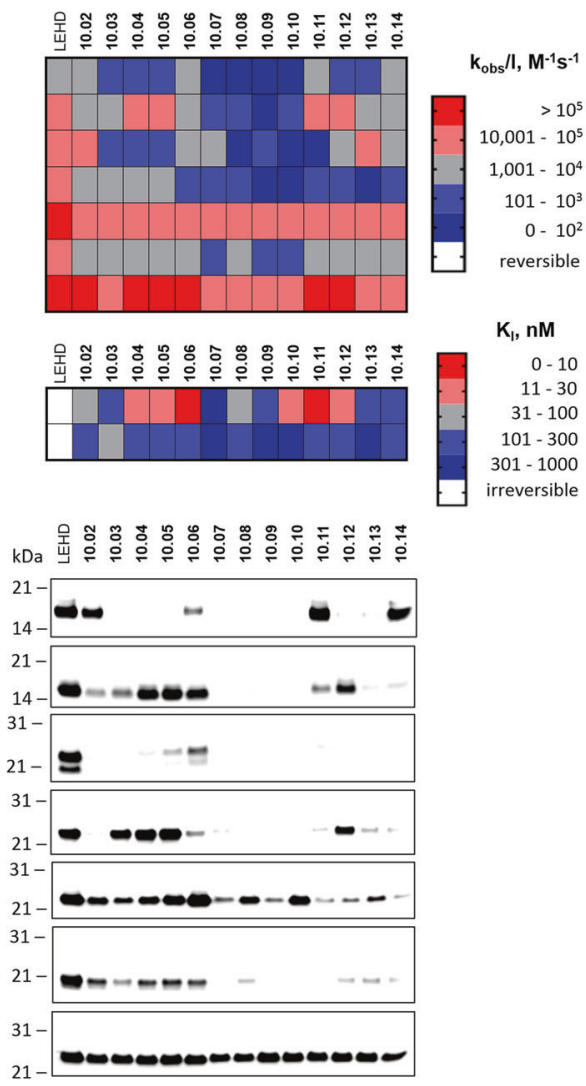

site-titrated caspases $(50 \mathrm{nM})$ for $30 \mathrm{~min}$, followed by SDS-PAGE, membrane transfer, and detection with fluorescent streptavidin. The lane on the left in each blot is a controlled broad-spectrum caspase probe (LEHD; biotin-ahx-LEHD-AOMK) used to ensure equivalent exposure between each blot

reactivity with the large catalytic subunit in western blots. Caspase-3 was cleaved and activated, as evidenced by PARP (poly(ADP-ribose) polymerase) cleavage to $96 \mathrm{kDa}$. Caspase-9 was cleaved to its signature p35 derivative, indicative of the processing by caspase- 3 , an activity that does not activate caspase-9 [31, 32].

To analyze the relationship between caspase- 8 processing and activation, we pre-treated Jurkat cells with biotinlabeled ABPs $(25 \mu \mathrm{M})$ for $2 \mathrm{~h}$, followed by TRAIL stimulation for $8 \mathrm{~h}$ (Fig. 5c). We then lysed the cells, captured biotinylated probe adducts with immobilized streptavidin, and detected the probe-binding caspase- 8 derivatives by immunoblotting with specific antisera. Three forms of caspase- 8 (p55, p43, and p18), all of which contain the catalytic nucleophile, were captured by ABPs, indicating that each is catalytically active. Interestingly, endogenous p43 and p18 subunits showed the same specificity, since both were comparably labeled with a panel of ABPs. Moreover, the relative efficiency of ABPs in binding caspase- 8 reflected their $k_{\mathrm{obs}} / I$ parameters (Fig. 5c), demonstrating that various forms of endogenous caspase- 8 

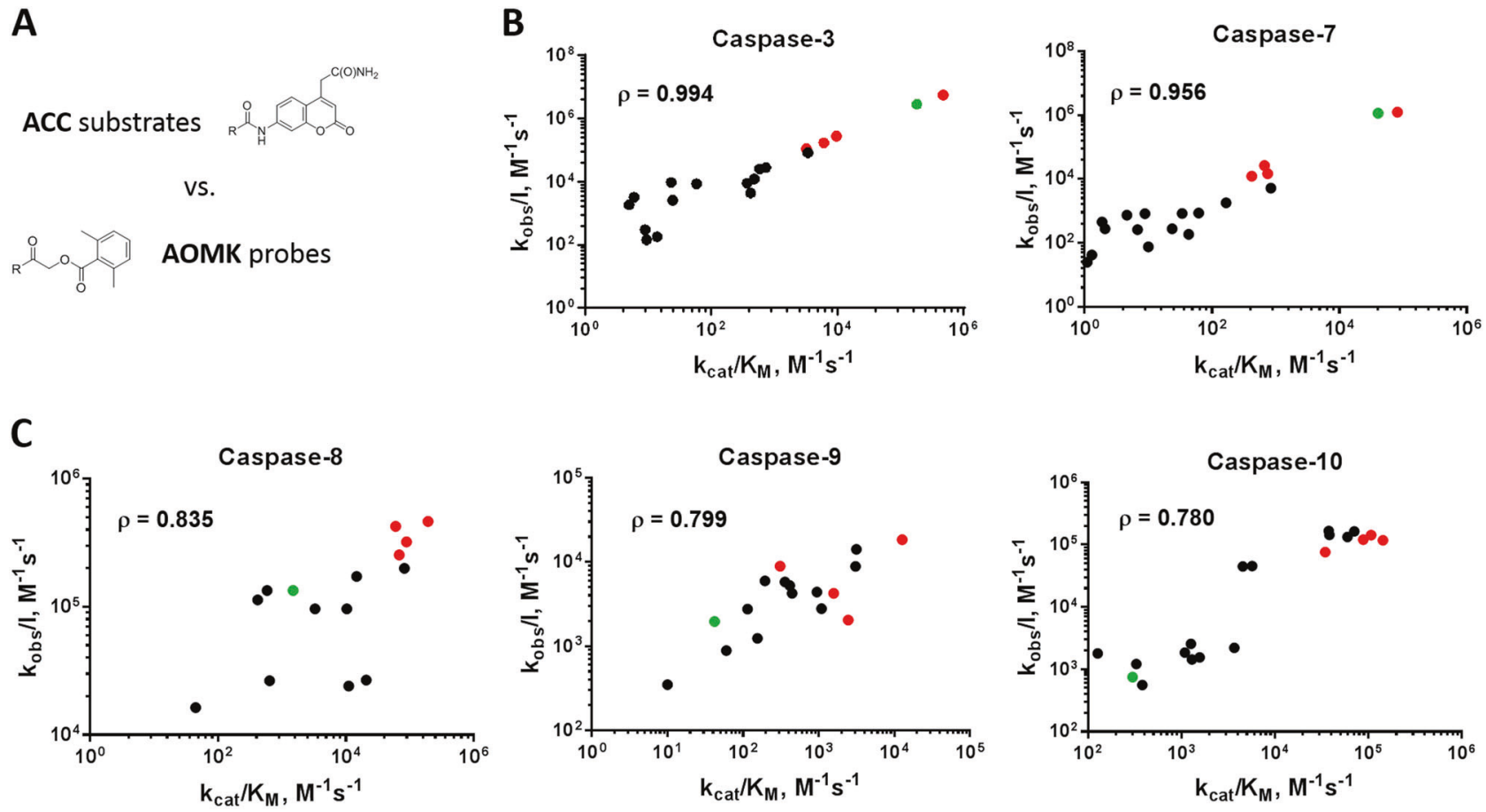

D

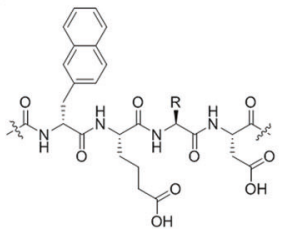

Fig. 4 Kinetic parameters of ACC substrates and AOMK-activitybased probes. a General structure of the substrate-leaving group and ABP electrophile. Correlation between $k_{\text {obs }} / I$ and $k_{\text {cat }} / K_{\mathrm{M}}$ for effector caspases-3 and -7 (b) and apical caspases- $8,-9$ and -10 (c). Red points show values obtained in the presence of broad-spectrum probes with peptide sequences DEVD, IETD, LEHD, or LQnD (where $\mathrm{n}$ is norleucine); green points indicate values obtained in the presence of a

have the same specificity as the recombinant $\triangle \mathrm{DED}$ (death effector domain) enzyme used here for kinetic studies.

To observe the activation kinetics of caspase- 8 and -3 in TRAIL-stimulated Jurkat $T$ cells, we also utilized several caspase ACC-labeled fluorescent substrates (Fig. 5d,e). These substrates are not cell-permeable, requiring us to optimize a buffer system to conduct the assay. To do so, we induced apoptosis with TRAIL, collected cells after $8 \mathrm{~h}$, permeabilized them with a panel of detergent-containing buffers, and then added Ac-DEVD-ACC substrate and monitored the hydrolysis over time. Based on permeabilization and hydrolysis outcomes, the best buffer was $0.5 \%$ Triton-X 100 in $1 \times$ caspase buffer (for components see Methods). Next, to monitor caspase activation kinetics, we stimulated Jurkat cells with TRAIL and assayed the activity at various time points using broad-spectrum caspase- 8 or caspase-10 selective ACC substrates in the presence of the optimized lysis buffer (Fig. 5d). Caspase-3 was fully active

E

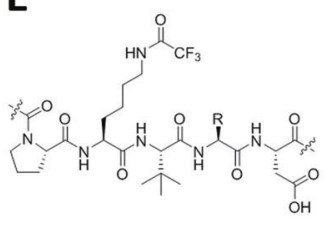

\begin{tabular}{ccc} 
& P2 Ala & P2 His \\
\hline $\begin{array}{c}\text { ACC substrate, } \\
\mathbf{k}_{\text {cat }} / \mathbf{K}_{\mathbf{M}}, \mathrm{M}^{-1} \mathbf{s}^{-1}\end{array}$ & 3,100 & 13,500 \\
\hline $\begin{array}{c}\text { AOMK probe, } \\
\mathbf{K}_{\mathbf{l}}, \mathrm{nM}\end{array}$ & 8.6 & 35.3 \\
\hline
\end{tabular}

MP-3.01, which are selective for effector caspases-3 and -7. Pearson correlation coefficients $(\rho)$ were calculated from linear kinetic parameters, and data were plotted as $\log / \log$ to demonstrate the spread of values. In the case of caspase-8 (d) and caspase-9 (e), His at P2 differentially influences the catalytic efficiency for a substrate versus an $\mathrm{ABP}$

between $1-2 \mathrm{~h}$ after TRAIL stimulation. Interestingly, we observed the same pattern of activation using the substrate Ac-IETD-ACC, which is generally used as a caspase- 8 reporter. In parallel, we utilized two caspase- 8 selective substrates $\quad\left(\mathrm{MP}-8.01 k_{\mathrm{cat}} / K_{\mathrm{M}}=25,700 \mathrm{M}^{-1} \mathrm{~s}^{-1}\right.$ and MP$8.04 k_{\text {cat }} / K_{\mathrm{M}}=10,400 \mathrm{M}^{-1} \mathrm{~s}^{-1}$; Table S5), both very poorly recognized by caspases-3 and -7 . Analysis of the cleavage profiles revealed that caspase- 8 is active within the same time frame as caspase-3, and remains active for at least $8 \mathrm{~h}$. This observation demonstrates that caspase- 8 remains active for extended periods after TRAIL ligation and argues against a potential caspase- 8 molecular timer mechanism similar to that proposed for caspase- 9 , whereby caspase- 8 would be activated to cleave caspases- 3 and -7 , and then become inactive [33].

To confirm that the fluorescent signal from MP-8.01 cleavage is caspase-8-dependent, we added two protein caspase inhibitors, XBIR2 and the viral protein CrmA. The 
A
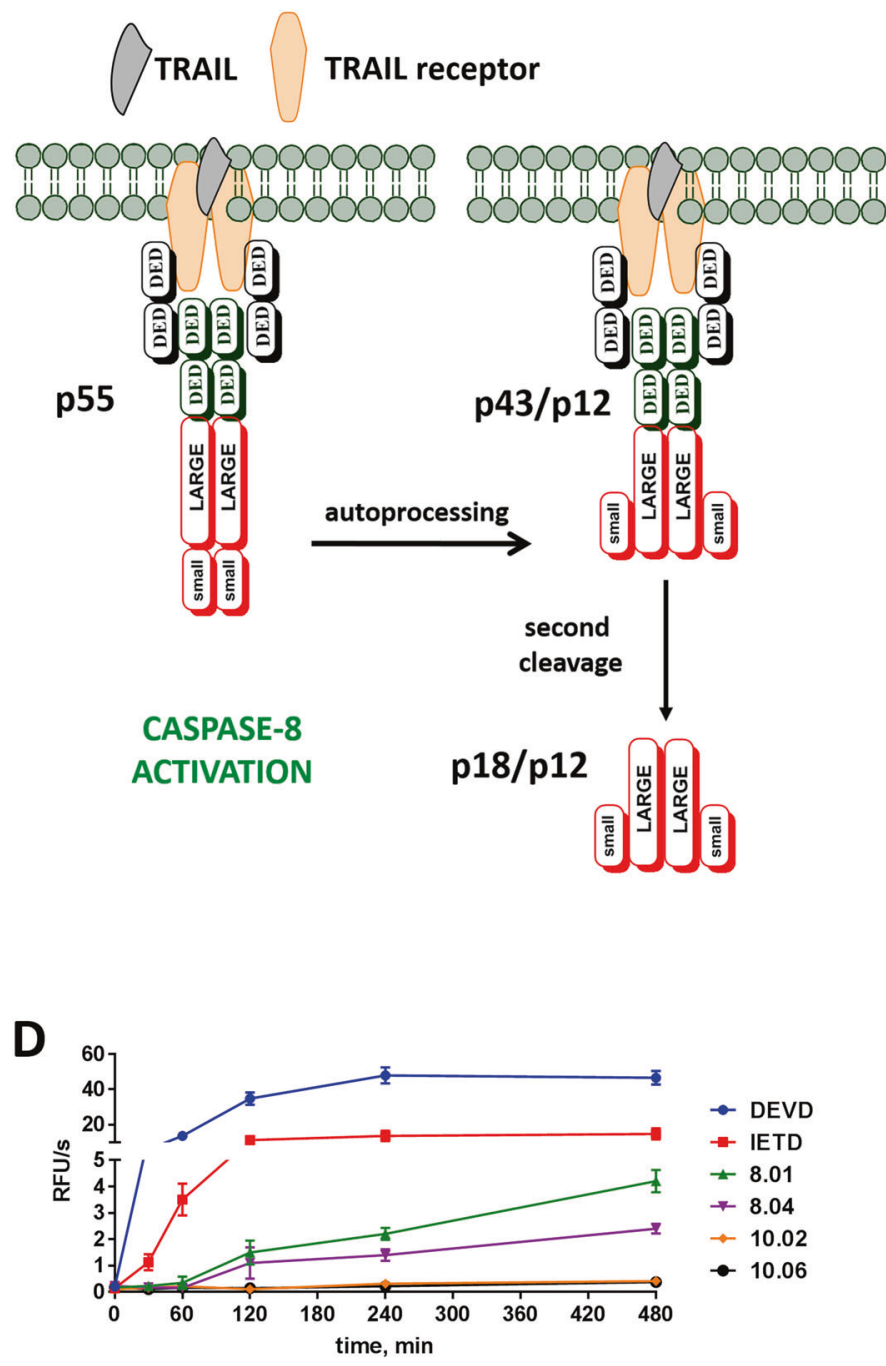

Fig. 5 Use of small-molecule substrates and ABPs reveals caspase activation in TRAIL-stimulated Jurkat T cells. a The general scheme of caspase-8 activation upon TRAIL stimulation. Procaspase-8 (p55) is activated by dimerization at the DISC and undergoes auto-processing within the catalytic domain to generate p43/p12 fragments, which are further cleaved by the release of the DEDD recruitment domain into p18/p12 subunits [65] Jurkat T cells primarily express caspase-8 isoforms $\mathrm{a}$ and $\mathrm{b}$, which differ by a short indel in the DED domain region, hence, the doublets seen in the $55 \mathrm{kDa}$ and $43 \mathrm{kDa}$ regions [66, 67] (of b,c) . b Western blots with specific antisera demonstrating the kinetics of caspase and PARP processing after TRAIL stimulation. The band around $20 \mathrm{kDa}$ in the caspase- 8 blot may be the p18 (large) subunit or a nonspecific band. c Cells were preincubated with indicated ABPs for

second BIR domain of XIAP (XBIR2) is exquisitely specific for effector caspases -3 and -7 , and CrmA is selective for caspase-8 over effector caspases [34-36]. XBIR2inhibited cleavage of DEVD and IETD substrates, but not MP-8.01, while CrmA only slightly inhibited DEVD and IETD cleavage, but substantially inhibited MP-8.01 cleavage (Fig. 5e). As a control, we stimulated FADD ${ }^{-1-}$ (Fas-
B
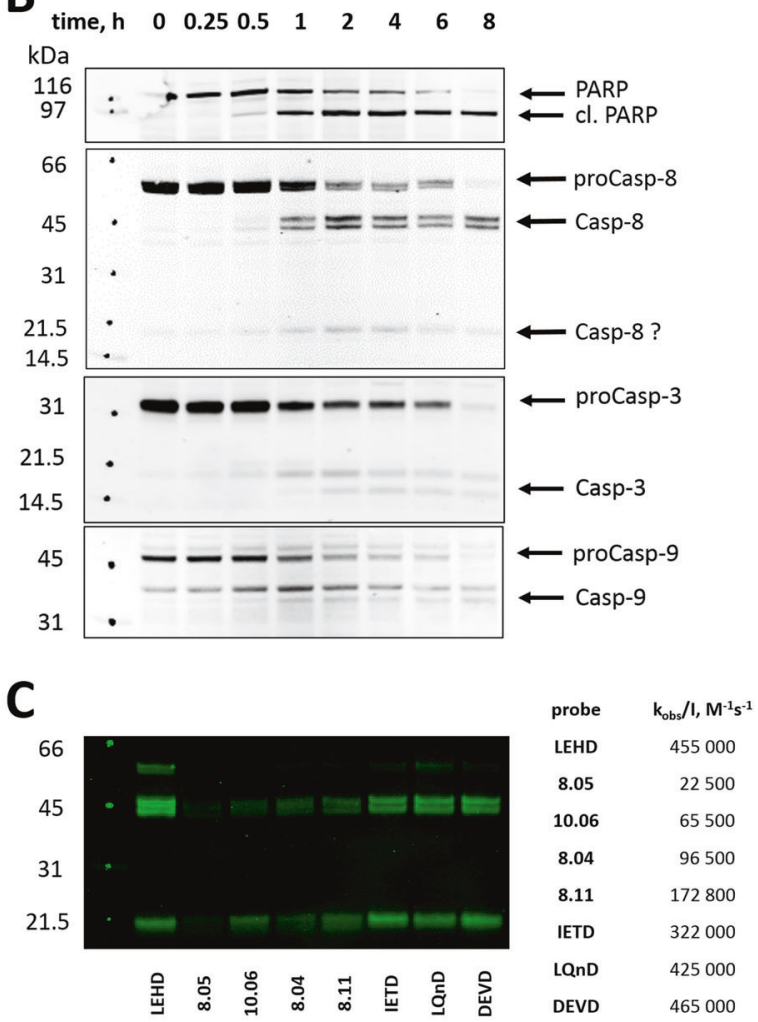

E

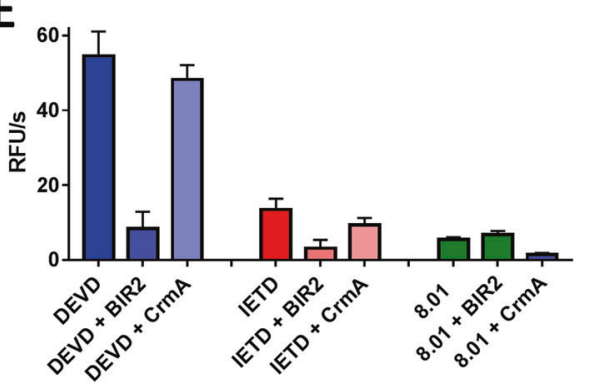

$2 \mathrm{~h}$ and stimulated for $8 \mathrm{~h}$ with TRAIL. Cell lysates were then prepared and treated with streptavidin resin, the resin was washed, and the captured proteins were then eluted in boiling SDS buffer and run on SDS-PAGE for immunoblotting with caspase- 8 antiserum. d Caspase activity in Jurkat cells at various time points after apoptosis induction and using indicated broad-spectrum and selective ACC substrates. e Caspase activity measured in Jurkat $\mathrm{T}$ cells at $8 \mathrm{~h}$ after apoptosis induction in the presence or absence of caspase inhibitors XBIR2 (1 $\mu \mathrm{M}$; for caspase-3/-7) and CrmA (1 $\mu \mathrm{M}$; for caspase-8). RFU relative fluorescence units. Western blots from $\mathbf{b}, \mathbf{c}$ were performed twice, and the kinetic experiments in $\mathbf{d}, \mathbf{e}$ were performed three times. Average values (with SD) are presented

associated protein with death domain; unable to activate apical caspases) or Casp- $8^{-/-}$Jurkat T cells with TRAIL for $8 \mathrm{~h}$ and were unable to detect caspase- 8 activity (Figure S3). Finally, given that two caspase-10 selective substrates (MP10.02 and MP-10.06) were not hydrolyzed (Fig. 5d), we concluded that, within the time range used here, caspase- 10 does not function in TRAIL-stimulated death of Jurkat 
T cells. In an orthogonal experiment, we used biotincapture to investigate whether caspase- 8 and caspase-10 selective ABPs could pull down the caspases from TRAIL-stimulated Jurkat $\mathrm{T}$ cells (as previously described for caspase-8) (Figure S4). The results demonstrated that caspase-3 was captured by almost all ABPs, except two (MP-8.04 and MP$10.07)$, which displayed poor $k_{\text {obs }} / I$ parameters. This was expected because caspase- 3 is the most active and abundant enzyme in caspases cascade. Furthermore, caspase- 8 was pulled down with only good and very good (high $k_{\text {obs }} / I$ ) probes, whereas labeling of active caspase-10 was almost negligible, even with potent probes displaying excellent inactivation rates $\left(k_{\mathrm{obs}} / I>100,000 \mathrm{M}^{-1} \mathrm{~s}^{-1}\right)$. Together, these data demonstrate that ABPs are useful for reflecting caspase activity, but even the most selective caspase- 8 probes synthesized to date are still not able to specifically label caspase8 because of the overwhelming activity and concentration of caspase-3, activated downstream from caspase-8.

\section{Use of a panel of activity-based probes to distinguish between apical caspases in extrinsic and intrinsic apoptosis}

Given that individual probes cannot be used to dissect the role of apical caspases, we initiated a combinatorial approach and selected a panel of probe sequences showing good inhibition of apical caspases- $-8,-9$, and -10 , but poor inhibition of the effector caspases- $3,-6$, and -7 , and treated Jurkat $\mathrm{T}$ cells for $24 \mathrm{~h}$ with TRAIL to engage the extrinsic pathway (Figure S5). Cells were pre-treated for $4 \mathrm{~h}$ with probes: in one set of experiments the probes were washed out before TRAIL addition, in the second set, the probes remained during the TRAIL incubation (Figure S5). We observed that only very potent and broad-spectrum probes (DEVD, LEHD, IETD) had some pro-survival effect, and other more selective, but less active probes had almost no impact on cell death.

To increase the efficiency of probe delivery, we used reversible permeabilization with digitonin, a reagent commonly used to allow molecules to penetrate the cell membranes [37]. To do so, we treated the cells with buffer containing 50\% RPMI 1640 medium $/ 50 \%$ digitonin in water (for $5 \mathrm{~min}$ ), since the brief treatment with hypotonic buffer can substantially enhance the uptake of peptides with minimal effect on cell viability, as we observed (Figure S6). Having optimized that assay, we treated cells with ABPs in the presence of digitonin, allowed them to recover for $24 \mathrm{~h}$, and then monitored the cell viability (Fig. 6a). None of the ABPs tested were toxic at a concentration of $25 \mu \mathrm{M}$ (Fig. 6b, panel "control"). We then investigated the effects on apoptosis by treating the cells for 5 min with $25 \mu \mathrm{M}$ of the same panel of ABPs in the presence of digitonin, replaced the medium, initiated apoptosis by TRAIL to engage the extrinsic pathway or etoposide to engage the intrinsic pathway for $24 \mathrm{~h}$, and measured the cell viability by an MTS assay (Fig. 6b; Figure S7). We found that several probes (mostly broad-spectrum) blocked apoptosis with high efficiency, while others displayed moderate or no pro-survival effects (Fig. 6b). We predicted that there should be a structure-activity relationship between probe efficiencies on recombinant caspases; thus we correlated the kinetic parameters $\left(k_{\mathrm{obs}} / I\right)$ of a diverse set of ABPs with their ability to rescue the cells from TRAIL-stimulated or etoposide-stimulated apoptosis (\% cell survival). We performed this analysis using only probes displaying high selectivity toward apical caspases, since even if apical caspases are activated, apoptosis is blocked by inhibition downstream caspases- 3 and -7 , and thus the use of broadspectrum probes may not provide accurate read-outs (Figure S5, S7, S8). In TRAIL-stimulated cells, we observed the highest correlation between ABP potency $\left(k_{\mathrm{obs}} / I\right.$ and also $K_{\mathrm{I}}$ ) and cell survival for the caspase-8 probe set (Fig. 6c; Figure S5). Interestingly, we did not observe a correlation between ABP potency toward caspase-10 and cell survival, supporting the idea that caspase-10 does not contribute to TRAIL-induced cell death in the presence of caspase-8. As expected, caspase- 9 also played no role in TRAIL-induced apoptosis because the caspase- 9 probe set failed to correlate with survival. Our findings confirm that caspases-3 and -7 are responsible for apoptosis execution, however, their activation was caspase-8 dependent (Fig. 6c; Figure S5B,C).

Relevant to etoposide-triggered apoptosis, we could not identify the key apical caspase(s) using our approach. We observed a good correlation between the caspases- 3 and -7 probe set and cell survival, but did not observe comparable correlations for other caspases. Analysis of caspase- 8 probes revealed a poor correlation dominated by broad-spectrum ABPs (DEVD, IETD, LEHD) that also target caspase-3. However, in contrast to TRAIL stimulation, we observed no correlation of ABPs with moderate $k_{\mathrm{obs}} / I$. As expected, we did not observe a correlation between etoposide-initiated cell death and caspase-10 selective probes, but unexpectedly could not correlate caspase- 9 activity with etoposideinduced apoptosis based on the correlations (Fig. 6c). Since, unlike caspases- 8 and -10 , caspase- 9 is activated within an apoptosome complex, AOMK ABPs may have had limited access to the endogenous caspase-9 active site, blunting the inhibition. To test this possibility, we used several caspase-9 ABPs, as well as some broad-spectrum probes (biotinylated DEVD, LEHD, and IETD) and zVADbased inhibitors (-fmk, -bzl, and -AOMK) in a cell-free apoptosis system, in which we stimulated the apoptosome assembly by addition of cytochrome c (Figure S9). All probes (broad-spectrum and caspase-9-selective) were very efficient in inhibiting recombinant human $\triangle$ CARD (caspase activation and recruitment domain) caspase-9 (Figure S9A), 
A

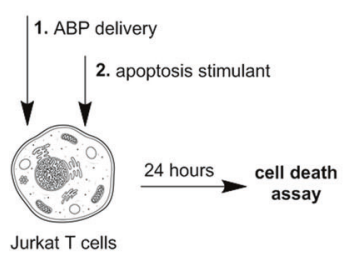

C

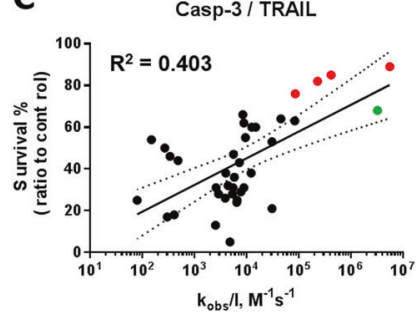

Casp-3 / etoposide
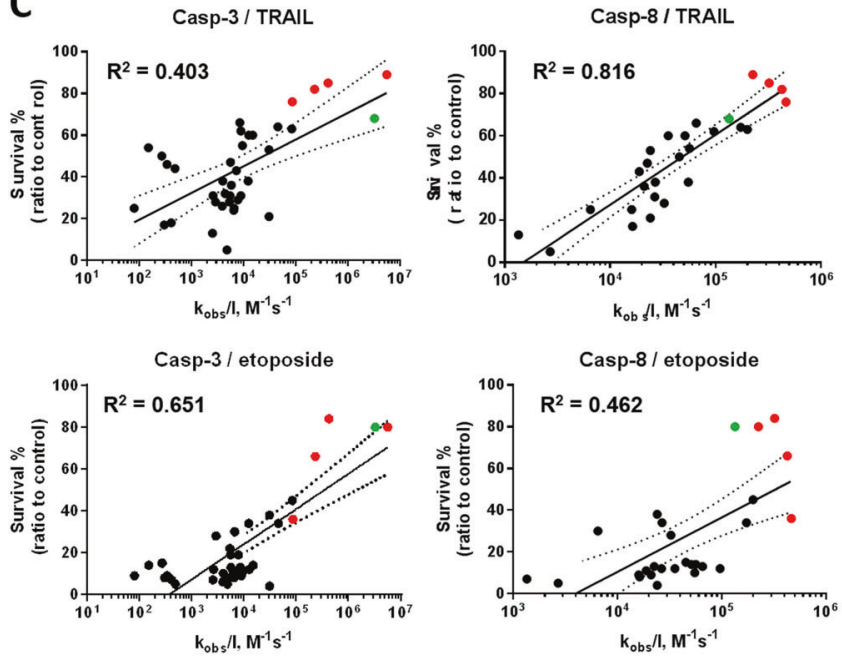

Fig. 6 Apoptosis induction in the Jurkat T cells as analyzed using a diverse set of ABPs. a Probes were delivered to cells by reversible permeabilization, followed by apoptosis induction by TRAIL or etoposide. After $24 \mathrm{~h}$, cell survival was measured relative to untreated controls using MTS assay. b Color-coded index of cell survival outcomes in the presence of a set diverse ABPs targeting caspases-8,- 9, and -10 tested in TRAIL- or etoposide-stimulated Jurkat T cells. c Correlation of probe inhibition potency $\left(k_{\mathrm{obs}} / I\right)$ and cell survival $(\%$,

but had only a small inhibitory effect on cytochrome ctriggered apoptosome activity, and delayed, but did not prevented caspase-3 processing and activation (Figure S9B, C). This data is consistent with previous observations that small-molecule probes are only minimally effective in inhibiting the apoptosome complex [38]. Based on this data, we conclude that AOMK probes may not be sufficient to inhibit endogenous caspase-9, and the high-cell survival ratios seen in etoposide-stimulated cells treated with select ABPs are likely attributable to the inhibition of downstream caspases-3 and -7 .

Our strategy demonstrates that it is possible to dissect the initiators of apoptosis with a panel of diverse ABPs, primarily because individual probes are not selective enough due to the overpowering influence of caspases-3 and -7. To determine whether this approach has wide validity, we explored it in breast cancer cell line MDA-MB-231. As these cells overexpress inhibitors of apoptosis proteins (IAPs), the induction of apoptosis via TRAIL pathway must be supported by the addition of an IAP antagonist (birinapant) (Figure S10A) [39]. We demonstrated that the preincubation of MDA-MB-231 cells with a panel of ABPs

survival \%

control to ratio

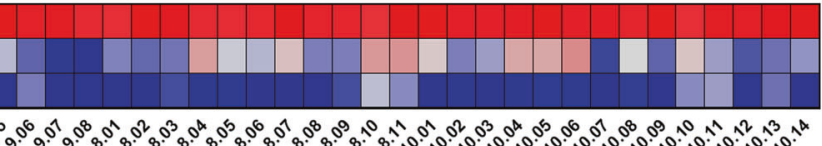

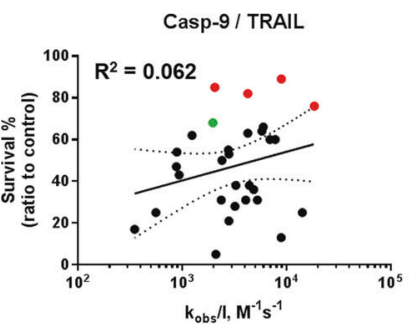
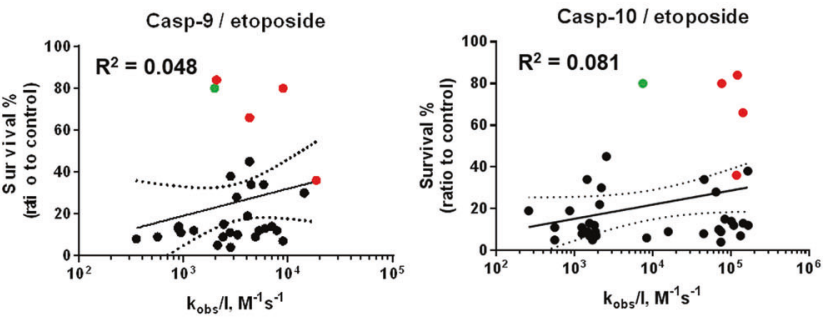

ratio to control). Red points show values obtained in the presence of broad-spectrum probes with peptide sequences DEVD, IETD, LEHD, or LQnD (where $\mathrm{n}$ is norleucine); green points indicate values obtained in the presence of a probe 3.01, which is selective for effector caspases-3 and -7. Each analysis contained the same probe panel set. Regression coefficients $\left(R^{2}\right)$ were calculated from semi-log plots, with dotted lines indicating $95 \%$ confidence interval

$(25 \mu \mathrm{M})$ for $4 \mathrm{~h}$, followed by washing the probes out and adding TRAIL/birinapant stimulants ( $24 \mathrm{~h}$ ) had only a small impact on cell survival (Figure S10B). However, when the probes were preincubated for $4 \mathrm{~h}$ without washout and then co-incubated with TRAIL/birinapant, their pro-survival effect was more pronounced (Figure S10B). The level of cell survival correlated well with $\mathrm{ABP} k_{\mathrm{obs}} / I$ parameters measured for caspase-8 (Pearson's correlation coefficient $=$ 0.775) (Figure S10C). Surprisingly, to achieve such a good anti-apoptotic effect, we did not have to use reversible permeabilization, presumably because the MDA-MB-231 cells were more permeable to ABPs than Jurkat cells. This striking difference between Jurkat $\mathrm{T}$ cells and MDA-MB231 cells shows that the dynamics of ABPs uptake may be cell dependent, which should be taken into account when working with other cell types.

\section{Discussion}

Defining precise functions of caspases in apoptotic responses to distinct stimuli is critical for our understanding 
of mechanisms that drive degenerative and proliferative diseases, as well as for design of therapeutic agents to either block or accelerate apoptosis. An obstacle in designing these tools has been overlapping substrate specificity: chemical-based attempts to distinguish the roles of closely related enzymes in a network are hampered by activity overlap. Hence, the goal is to exploit minor differences in specificity.

Biochemical characterization of recombinant caspases and structural analysis over the last decade has provided a framework for synthesis of chemical tools now widely used in biological studies of these enzymes. Yet, as pointed out previously, the most popular reagents remain non-selective and have not yet yielded the required precision [11, 12, 40, 41]. For example, here we demonstrate that the use of LEHD and IETD-based probes, which are commonly used to analyze or even distinguish between apical caspases provide an incomplete picture, since they target effector caspases with similar efficiencies (Fig. 3) and cannot distinguish cell death mechanisms (Fig. 6, red dots on graphs). To enhance selectivity, we and others previously demonstrated that the use of unnatural amino acids significantly increases selectivity of substrates and peptide inhibitors toward individual apoptotic caspases [13, 16, 24, 42, 43]. We utilized substrate-based HyCoSuL data to design small molecule, biotin-labeled ABPs with high selectivity toward the apical caspases- $8,-9$, and -10 . Their selectivity has been demonstrated by measuring the kinetic parameters toward individual enzymes and in affinity-labeling assays (Fig. 3). Interestingly, in this paper, we demonstrate that ABP kinetic parameters strongly correlate with cleavage efficiency of fluorogenic substrates with corresponding sequences. By this, we confirm the general rule that good substrates and be converted into good inhibitors. However, we also found that caspase-8 and caspase-9 displayed an activity switch between substrates and probes harboring His at P2 position. Although substrates with P2 His are preferred by these caspases, corresponding inhibitors display only moderate potency. We hypothesize that the His switch feature is associated with different mechanisms of substrate recognition and inhibitor binding. We also observed that some ABPs show different inhibition kinetics in interacting with caspase-8 or -9 , compared to caspase-10. Differential inhibitory mechanisms associated with probes with an AOMK warhead have been reported previously [25, 44], but the reason is unknown, and why caspase-10 behaves differently than its close paralog caspase- 8 awaits future analysis.

We also observed that caspase peptidyl substrates are more selective than the corresponding probes. For example, we discovered a highly selective substrate useful to detect caspase-8 activity following TRAIL-induced apoptosis (Fig. 5). Significant selectivity is lost after conversion of highly selective substrates to ABPs, suggesting that single
ABPs cannot be used to label an individual apical caspase or specifically inhibit it. Nevertheless, selectivity can be assessed by calculating the second-order reaction rates, irrespective of the reaction mechanism, in order to generate structure-activity relationships for a panel of probes. Based on this approach, we conclude that caspase- 8 , and not caspase-10, is primarily involved in Jurkat $\mathrm{T}$ cell apoptosis induced by TRAIL, a finding consistent with genetic models that rule out a role for caspase-10 in extrinsic death signals $[45,46]$.

Finally, being unable to use individual caspase-selective ABPs in cells due to the overpowering influence of caspases-3 and -7, we designed the ABP panel approach to establish a functional assay to detect caspase activation in apoptotic cells. Many ABPs are not cell penetrant, and we found that reversible permeabilization with digitonin enhances probe delivery to Jurkat $\mathrm{T}$ cells, indicating that this assay could be adapted to various cancer cell lines when apoptosis (or cell death in general) is induced using different stimuli. Importantly, our set of ABPs contains several caspase-10 selective probes; therefore, it may be possible to define either cancer cell lines dependent on caspase-10 or reagents that stimulate apoptosis mediated by caspase- 10 . Finally, we validated our assay in breast cancer cell line MDA-MB-231. However, our experiments suggested that with this cell line, passive ABP delivery to the cytosol is sufficient to block caspase-dependent cell death. As in Jurkats, MDA-MB-231cell survival shows the strongest correlation with ABPs directed against caspase-8. Since our functional assay depends on caspase activity, it should be possible to determine whether the cells evade apoptosis and switch to caspase-independent cell death paradigms such as necrosis, autophagy, or mitotic catastrophe [47-49].

\section{Materials and methods}

\section{Reagents}

All chemicals and reagents were purchased from commercial suppliers and used without further purification, unless otherwise noted. Fmoc-protected amino acids were purchased from Sigma-Aldrich (Poznan, Poland), Iris Biotech GmbH (Marktredwitz, Germany), Creosalus (Louisville, KY, USA), Bachem (Torrance, CA, USA), and PE Biosciences Limited (Hong Kong, China). Fmoc-ACC-OH was synthesized according to a previously published method [13, 50]. Biotin, 2-chlorotrityl chloride resin (particle size 100-200 mesh, $1.59 \mathrm{mmol} / \mathrm{g}$ ), Rink Amide RA resin (particle size $200-300 \mathrm{mesh}, 0.7 \mathrm{mmol} / \mathrm{g}$ ), coupling reagents (HBTU and HATU), piperidine (PIP), trifluoroacetic acid (TFA), and diisopropylcarbodiimide (DICI) were purchased from Iris Biotech $\mathrm{GmbH}$. Anhydrous $\mathrm{HOBt}$ was purchased 
from Creosalus (Louisville, KY, USA). $N, N$-diisopropylethylamine (DIPEA), 2,4,6-trimethylpyridine (2,4,6-collidine), acetonitrile for HPLC, triisopropylsilane (TIPS), 2,2,2-trifluoroethanol (TFE), hydrobromic acid solution $(30 \% \mathrm{HBr}$ wt. in $\mathrm{AcOH})$, anhydrous tetrahydrofuran (THF), 4-methylmorpholine (NMM), isobutylchloroformate (IBCF), and 2,6-dimethylbenzoic acid (2,6-DMBA) were all from Sigma-Aldrich. $N, N^{\prime}$-dimethylformamide (DMF), dichloromethane (DCM), methanol $(\mathrm{MeOH})$, diethyl ether $\left(\mathrm{Et}_{2} \mathrm{O}\right)$, acetic acid $(\mathrm{AcOH})$, and phosphorus pentoxide $\left(\mathrm{P}_{2} \mathrm{O}_{5}\right)$ were obtained from POCh (Gliwice, Poland). Diazomethane was generated following the Aldrich Technical Bulletin (AL-180) procedure. All peptides, ACC substrates, and biotin-labeled AOMK ABPs were purified by HPLC on a Waters system (Waters M600 solvent delivery module, Waters M2489 detector system) using a semi-preparative Discovery ${ }^{\oplus}$ C8 HPLC column (particle size $10 \mu \mathrm{m}$ ) to at least $95 \%$ of purity (confirmed by analytical HPLC using an analytical Discovery ${ }^{\circ}$ C8 column (particle size $10 \mu \mathrm{m}$ ). Solvent composition used for semi-preparative and analytical methods was as follows: phase A (water with $0.1 \%$ TFA), phase B (acetonitrile with $0.1 \%$ TFA). A linear gradient of an increasing concentration of phase B was applied. The molecular weight of each compound was confirmed using a High Resolution Mass Spectrometer WATERS LCT premier XE with electrospray ionization (ESI) and time-of-flight (TOF) module.

\section{Cell culture, apoptosis inducers, and antibodies}

Human Jurkat $\mathrm{T}$ cells, caspase-8-deficient Jurkat $\mathrm{T}$ cells, and FADD-deficient Jurkat $\mathrm{T}$ cells were cultured in RPMI 1640 (Corning Cellgro) supplemented with 10\% fetal bovine serum (FBS, Atlas Biologicals), $2 \mathrm{mM}$ L-glutamine (Omega Scientific), 100 units $/ \mathrm{mL}$ penicillin, and $10 \mu \mathrm{g} / \mathrm{mL}$ streptomycin (both Gibco Life Technologies) in a humidified $5 \% \mathrm{CO}_{2}$ atmosphere at $37^{\circ} \mathrm{C}$. Jurkat cell apoptosis was induced using KillerTRAIL ${ }^{\mathrm{TM}}$ (Enzo Life Sciences) or etoposide (MP Biomoedicals, LLC). Birinapant, a SMAC mimetic, was purchased from Cayman Chemicals (Cat No. 19699). Caspase-3 antibody was from Cell Signaling (rabbit ab, Cat No. 9662S); caspase-9 antibody (polyclonal, rabbit), raised against recombinant catalytic domain, was as previously described; [51] monoclonal caspase-8 antibody C15 raised against an epitope of the large subunit [52] was a kind gift of Dr. Markus Peter, University of Chicago; caspase-10 antibody was from MBL Life Science (mouse, Cat No. M059-3); PARP antibody was purchased from BDPharmigen (mouse, Cat No. 556362). Human MDA-MB231 breast cancer cells were cultured in Dulbecco's Modification of Eagle's Medium (DMEM) supplemented with $10 \%$ of fetal bovine serum, $2 \mathrm{mM}$ of L-glutamine, 100 units $/ \mathrm{mL}$ penicillin, and $100 \mu \mathrm{g} / \mathrm{mL}$ streptomycin.

\section{ABP design and synthesis}

Based on PS-SCL and HyCoSuL data, we designed and synthesized 38 ABPs targeting five human apoptotic caspases $[4,13]$. The general structure of each was biotinahx-P4-P3-P2-P1-AOMK. These 38 probes comprised five classes: (1) 4 broad-spectrum probes for all five caspases (P4-P1 sequence: DEVD, LEHD, IETD, and LQnD), (2) 1 caspase-3/-7 selective probe (bMP-3.01), (3) 8 caspase-9 selective probes (bMP-9.01...9.08), (4) 11 caspase- 8 selective probes (bMP-8.01..8.11), and (5) 14 caspase10 selective probes (bMP-10.01...10.14). The method used to synthesize AOMK probes with P1 Asp is described elsewhere [53]. In brief, a biotin-ahx-P4-P3-P2-COOH peptide was synthesized on a solid support (2-chlorotrityl chloride resin) and used for further synthesis without purification. In a separate synthesis, $\operatorname{Boc}-\mathrm{Asp}(O-\mathrm{Bzl})$ AOMK was obtained through reaction of $\operatorname{Boc}-\operatorname{Asp}(O$ Bzl)-COOH with diazomethane, followed by conversion of $\operatorname{Boc}-\mathrm{Asp}(\mathrm{O}-\mathrm{Bzl})-\mathrm{CHN}_{2}$ to bromomethyl ketone $\left(-\mathrm{CH}_{2} \mathrm{Br}\right)$ and finally to acyloxymethyl ketone (-AOMK). Next, Boc-Asp $(O-B z l)-A O M K$ was de-protected with TFA to obtain $\mathrm{H}_{2} \mathrm{~N}$-Asp $(O$-Bzl $)$-AOMK. The $N$-de-protected warhead was then coupled to biotin-ahx-P4-P3-P2$\mathrm{AOOH}$ to obtain biotin-ahx-P4-P3-P2-Asp $(O-\mathrm{Bzl})$ AOMK. The protecting groups from $\mathrm{P} 4-\mathrm{P} 2$ amino acids were removed using TFA and $\operatorname{Asp}(O$-Bzl $)$ was deprotected via hydrogenolysis $\left(\mathrm{Pd} / \mathrm{C}, \mathrm{H}_{2}\right.$, inert atmosphere). The final crude product was purified by RP-HPLC using a C8 column.

\section{Recombinant caspase assay conditions}

Human apoptotic caspases were expressed and purified as described [51]. Before kinetic analysis, all caspases were active site-titrated using the zVAD-fmk inhibitor (Cayman Chemical Company, Cat No. 14467), according to the protocol described by Stennicke and Salvesen [51]. Caspase assay buffer composition: $20 \mathrm{mM}$ PIPES, $10 \mathrm{mM} \mathrm{NaCl}, 1$ $\mathrm{mM}$ EDTA, $10 \% \mathrm{w} / \mathrm{v}$ sucrose, and $10 \mathrm{mM}$ DTT. To allow caspase-2, $-8,-9$, or -10 dimerization and maintain high activity, buffers were supplemented with $0.75 \mathrm{M}$ sodium citrate. Unless otherwise stated, the kinetic experiments were performed at $\mathrm{pH}$ 7.2.

\section{Recombinant cathepsin L and B assay conditions}

Human recombinant cathepsins $\mathrm{L}$ and $\mathrm{B}$ were a kind gift from Drs. Boris Turk and Matej Vizovisek, University of Ljubljana. Detailed description of the expression and the purification can be found elsewhere [54]. The concentration of active cathepsins were determined via titration with the irreversible inhibitor E64 (Peptide Institute). 


\section{Determination of ABP kinetic parameters}

Based on the kinetic analysis, we divided ABPs into three categories: (1) irreversible $-k_{\text {obs }} / I$, (2) tight-binding reversible $-\mathrm{K}_{\mathrm{I}}$, and (3) bimodal (both $k_{\mathrm{obs}} / I$ and $K_{\mathrm{I}}$ ). We determined $k_{\mathrm{obs}} / I$ (pseudo first-order kinetic constant; $Y=\left(V_{0}-V_{\mathrm{S}}\right) \times(1$ $\left.-\exp \left(-k_{\mathrm{obs}}\right)\right) / k_{\mathrm{obs}}+V_{\mathrm{S}} \times X$, where $Y$ is enzyme activity, $V_{0}$ is initial enzyme activity, and $V_{\mathrm{S}}$ is enzyme activity in the equilibrium state). $K_{\mathrm{I}}$ parameters were calculated using the Morrison equation [55]. For each caspase, an appropriate ACC-labeled substrate was used to monitor the reaction progress (caspase-2, Ac-VDVAD-ACC, $K_{\mathrm{M}}=11 \mu \mathrm{M}$; caspase-3, Ac-DEVD-ACC, $K_{\mathrm{M}}=21 \mu \mathrm{M}$; caspase-6, AcDEVD-ACC, $K_{\mathrm{M}}=468 \mu \mathrm{M}$; caspase-7, Ac-DEVD-ACC, $K_{\mathrm{M}}=57 \mu \mathrm{M}$; caspase- 8 , Ac-LEHD-ACC, $K_{\mathrm{M}}=15 \mu \mathrm{M}$; caspase-9, Ac-LEHD-ACC, $K_{\mathrm{M}}=106 \mu \mathrm{M}$; and caspase-10, AcLEHD-ACC, $K_{\mathrm{M}}=24 \mu \mathrm{M}$ ). For cathepsins $\mathrm{L}$ and B, we used the substrate Z-FR-AMC to monitor the reaction progress (cathepsin L, $K_{\mathrm{M}}=3.3 \mu \mathrm{M}$ and cathepsin B, $K_{\mathrm{M}}=62 \mu \mathrm{M}$ ). In all assays, the lowest inhibitor concentration was at least fourfold higher than the caspase concentration. In brief, to determine inhibition parameters, the inhibitor was diluted into wells on a 96-well plate, mixed with the substrate, and the plates were preincubated at $37^{\circ} \mathrm{C}$. Separately, caspase was preincubated at $37^{\circ} \mathrm{C}$, and after $15 \mathrm{~min}$, the enzyme was added and fluorescence was monitored for $30 \mathrm{~min}$, starting immediately. Both kinetic parameters $\left(k_{\mathrm{obs}} / I\right.$ for caspases-3, $-7,-8,-9$, and -10 , and $K_{\mathrm{I}}$ for caspase- 8 , and -9 ) were determined in at least three independent experiments and presented as an average value. All assays were performed using a CLARIOstar plate reader (BMG Labtech), operating in the kinetic mode ( $355 \mathrm{~nm}$ excitation, $460 \mathrm{~nm}$ emission, gain 650) using 96-well plates (Corning, NY, USA).

\section{Analysis of probe binding to recombinant caspases and cathepsins}

To assess ABP selectivity, $50 \mathrm{nM}$ of each zVAD-fmk active site-titrated recombinant caspases and E64 active sitetitrated recombinant cathepsin $\mathrm{L}$ and $\mathrm{B}$ were incubated with $100 \mathrm{nM}$ probe for $30 \mathrm{~min}$ at $37^{\circ} \mathrm{C}$ (reaction volume 200 $\mu \mathrm{L})$, next, the reaction products were precipitated as follows: $100 \mu \mathrm{L}$ of ice-cold $30 \%$ trichloroacetic acid (TCA) was added to each sample, incubated on ice for $30 \mathrm{~min}$, and centrifuged for $30 \mathrm{~min}\left(20,000 \times g, 4{ }^{\circ} \mathrm{C}\right)$. Supernatants were gently aspirated using a vacuum device, the pellet was re-suspended in $200 \mu \mathrm{L}$ ice-cold $10 \%$ TCA, and the samples were re-centrifuged for $15 \mathrm{~min}\left(20,000 \times g, 4{ }^{\circ} \mathrm{C}\right)$. Supernatants were again removed, and the pellet was resuspended in $200 \mu \mathrm{L}$ of acetone. Samples were centrifuged for $10 \mathrm{~min}\left(20,000 \times g, 4^{\circ} \mathrm{C}\right)$ and the supernatant was removed. Samples were dried at $37{ }^{\circ} \mathrm{C}$ for $15 \mathrm{~min}$, and then $80 \mu \mathrm{L}$ of $1 \times$ SDS/DTT buffer was added to each, followed by denaturation at $95{ }^{\circ} \mathrm{C}$ for $5 \mathrm{~min}$. The samples $(20 \mu \mathrm{L})$ were subjected to SDS-PAGE (30 min, $200 \mathrm{~V})$, followed by their transfer to a nitrocellulose membrane (60 min, $10 \mathrm{~V}$ ) and blocking with $2 \%$ BSA in TBS-T (60 min, RT). The biotin-labeled probe/caspase complex was detected by probing the membrane with fluorescently labeled streptavidin (30 min, RT, 1:10,000, IRDye $800 \mathrm{CW}$, LICOR), followed by scanning in LI-COR system $(800 \mathrm{~nm}$ channel, Odyssey ${ }^{\bullet} \mathrm{CLx}$, Lincoln, NE, USA). The data were analyzed using Image Studio Lite software (Lincoln, NE, USA). To better demonstrate the discrepancy between caspases and cathepsin bands from biotin-ahx-LEHDAOMK and biotin-ahx-DEVD-AOMK, labeling were quantified and presented in relative fluorescence units.

\section{Determination of the substrate kinetic parameters}

Substrate kinetic parameters $\left(k_{\mathrm{cat}}, K_{\mathrm{M}}, k_{\mathrm{cat}} / K_{\mathrm{M}}\right)$ were determined as described by Poreba et al. $[13,56]$. Measurements were performed using a CLARIOstar plate reader (BMG LABTECH, Cary, NC, USA), operating in the fluorescence mode (for ACC fluorescent tags $355 \mathrm{~nm} /$ excitation and 460 $\mathrm{nm} /$ emission wavelengths were used). Substrate hydrolysis was monitored for up to $30 \mathrm{~min}$, and most linear segment of plots were analyzed. Statistical analysis was performed using GraphPad Prism 7 software (La Jolla, CA, USA).

\section{Stimulation of the Jurkat T cells with TRAIL and etoposide}

Jurkat $\mathrm{T}$ cells $\left(5 \times 10^{5} /\right.$ well $)$ were placed on a 24 -well plate with fresh medium $(500 \mu \mathrm{L} /$ well $)$, and after $1 \mathrm{~h}$, apoptosis was induced by treatment with either $100 \mathrm{ng} / \mathrm{mL}$ TRAIL or $25 \mu \mathrm{M}$ etoposide $24 \mathrm{~h}$. At $0,0.5,1,2,4,8,12$, and $24 \mathrm{~h}$ time points, cells were collected and centrifuged at $500 \times g$ for 5 min. The supernatants were discarded, and the pellet was washed with 1× DPBS (Dulbecco's Phosphate Buffered Saline). Cells were re-centrifuged at $500 \times g$ for $5 \mathrm{~min}$, and the pellet was solubilized in $100 \mu \mathrm{L} 1 \times \mathrm{SDS} / \mathrm{DTT}$, heated to $95{ }^{\circ} \mathrm{C}$ for $5 \mathrm{~min}$, cooled to room temperature, and sonicated (Branson Sonifier 250). A $30 \mu \mathrm{L}$ sample aliquot was loaded onto a 4-12\% gel (Bis-Tris Plus) and electrophoresed for $30 \mathrm{~min}$ at $200 \mathrm{~V}$. Proteins were transferred to a nitrocellulose membrane $(0.2 \mu \mathrm{m}$, BIO-RAD) for $60 \mathrm{~min}$ at $10 \mathrm{~V}$, followed by Ponceau staining to verify equal loading and transfer. The membrane was blocked with $2 \%$ BSA in TBS$\mathrm{T}$ for $60 \mathrm{~min}$ at room temperature. Caspase activation and PARP cleavage were detected using primary antibodies (anti-caspase-3 1:1,000, anti-caspase-8 1:500, anti-caspase9 1:10,000, and PARP 1:2,000) incubated overnight at $4{ }^{\circ} \mathrm{C}$, followed by the incubation with fluorescent secondary antibodies (for caspase-3 and caspase-9, donkey anti-rabbit, IRDye 680RD, 1:10,000; for caspase-8 and PARP, donkey 
anti-mouse, IRDye $\left.{ }^{\oplus} 800 \mathrm{CW}, 1: 10,000\right)$ at room temperature for $30 \mathrm{~min}$. The membrane was scanned using the LI-COR system (700 $\mathrm{nm}$ and $800 \mathrm{~nm}$ channels), and the data were analyzed using Image Studio Lite software. To detect the 3 caspases plus PARP (and cleavage products) on the membranes, we performed two Western blot analyses for each apoptotic stimulant (membrane A: caspase-3, and caspase8; and membrane B: caspase-9 and PARP). Both membranes were incubated with appropriate secondary antibodies and scanned sequentially.

\section{Detection of caspase-3, -8 , and -10 in apoptotic Jurkat T cells}

To assess the specificity of endogenous caspases-3, -8 , and -10 , Jurkat T cells $\left(2 \times 10^{7}\right)$ were re-suspended in $2 \mathrm{~mL}$ fresh medium, and preincubated each for $2 \mathrm{~h}$ with $25 \mu \mathrm{M}$ biotinlabeled ABP. After this time, all non-internalized probes were washed out by centrifugation $(500 \times g$ for $5 \mathrm{~min})$ and the cells were re-suspended in fresh media $(2 \mathrm{~mL})$. Cells were then stimulated for $8 \mathrm{~h}$ with TRAIL (100 ng/mL), followed by centrifugation at $500 \times g$ for $5 \mathrm{~min}$. The pellet was washed with PBS and the cells re-centrifuged at $500 \times g$ for $5 \mathrm{~min}$. The resulting pellet was lysed in $200 \mu \mathrm{L}$ RIPA buffer and centrifuged at $20,000 \times g$ for $15 \mathrm{~min}$. The supernatant was transferred to a new tube and agitated for $4 \mathrm{~h}$ at $4{ }^{\circ} \mathrm{C}$ with 50 $\mu \mathrm{L}$ streptavidin agarose resin (50\% slurry). Samples were then centrifuged at $500 \times g$ for $5 \mathrm{~min}$, washed three times with lysis buffer (after each washing step, cells were centrifuged as above), and then $100 \mu \mathrm{L} 1 \mathrm{xSDS} / \mathrm{DTT}$ was added to the resin pellet and the mixture was boiled $5 \mathrm{~min}$. Lysate proteins were resolved on SDS-PAGE, followed by immunoblotting, as described above (caspase-3 and caspase-8). Caspase-10 was detected with anti-caspase-10 antibody (1:500) incubated overnight at $4{ }^{\circ} \mathrm{C}$, followed by incubation with fluorescent secondary antibody (donkey anti-mouse, IRDye $800 \mathrm{CW}, 1: 10,000)$ at room temperature for $30 \mathrm{~min}$.

\section{Screening of caspase- 8 and -10 selective substrates}

Recombinant caspases-3, -8, and -10 were pre-activated for $15 \mathrm{~min}$ at $37^{\circ} \mathrm{C}$ and then mixed with ACC-labeled substrates (final substrate concentration, $20 \mu \mathrm{M}$; final caspase concentration, $50 \mathrm{nM}$ ). Substrate hydrolysis was monitored using a plate reader, as described above. The linear regions of the curves (10-15 min) were evaluated, and results were presented as RFU/s values.

\section{Use of fluorescent substrates to detect caspase activity in apoptotic Jurkat $\mathrm{T}$ cells}

Jurkat T cells $\left(5 \times 10^{6}\right)$ were seeded in 96-well white, flat bottomed plates in phenol red-free RPMI hypotonic buffer
( $70 \mu \mathrm{L} /$ well) and stimulated for $8 \mathrm{~h}$ with TRAIL $(10 \mu \mathrm{L}$, final conc. $100 \mathrm{ng} / \mathrm{mL}$ ). Then, $20 \mu \mathrm{L}$ of $500 \mu \mathrm{M}$ Ac-DEVDACC dissolved in test lysis buffers was (Fig. 5d) added to the cells, and caspase activity was measured over $30 \mathrm{~min}$. Caspase buffer containing $0.5 \%$ Triton-X (which resulted in the highest fluorescence signal) was used in further analyses. Jurkat T cells $\left(5 \times 10^{6} /\right.$ well $)$ were then stimulated with TRAIL for $0,0.5,1,2,4$, and $8 \mathrm{~h}$, and at each time point, the caspase activity (RFU/s) was measured in the presence of $100 \mu \mathrm{M}$ ACC-labeled caspase substrates in the indicated buffer. Substrates included: caspase-3/7 Ac-DEVD-ACC substrate, a broad-spectrum Ac-IETD-ACC substrate, caspase-8-selective MP-8.01 and MP-8.04 substrates, and caspase-10 selective MP-10.02 and MP-10.06 substrates. DEVD, IETD, and MP-8.01 substrate selectivity was confirmed in a separate experiment, in which the cells were stimulated with TRAIL for $8 \mathrm{~h}$, followed by the addition of ACC substrate in the presence of the caspase inhibitors XBIR2 (1 $\mu \mathrm{M}$; for caspase-3/-7) and CrmA ( $1 \mu \mathrm{M}$; for caspase-8). In this experiment, fluorescence was read after $15 \mathrm{~min}$ of inhibitor/substrate addition to allow caspase inactivation. Analysis was also performed in Casp- $8^{-/-}$and FADD $^{-1-}$ Jurkat $\mathrm{T}$ cells. Kinetic experiments were performed on a CLARIOstar instrument $(350 \mathrm{~nm}$ excitation, $460 \mathrm{~nm}$ emission, gain 650), and the data were analyzed using GraphPad Prism software.

\section{Optimization of digitonin-assisted Jurkat $\mathbf{T}$ cells permeabilization}

Five hundred micro liter Jurkat $\mathrm{T}$ cells $\left(2.5 \times 10^{6}\right)$ were incubated in 12-well plates with $1 \mu \mathrm{M}$ FAM-LEHD-AOMK fluorescent probe in the presence of digitonin at various concentrations $(0,5,10,20,40 \mu \mathrm{g} / \mathrm{mL})$ in phenol red-free RPMI hypotonic buffer (RPMI to distilled water ratio $=1: 0$, $3: 1,2: 2,1: 3$ ) for 2,5 , or $10 \mathrm{~min}$. Then, $1 \mathrm{~mL}$ RMPI was added to the wells, and the cells were collected and centrifuged at $500 \times g$ for $5 \mathrm{~min}$. Supernatants were aspirated using a vacuum device and the pellets were re-suspended in $500 \mu \mathrm{L}$ RPMI. Cells were allowed to recover for $2 \mathrm{~h}$ in a $5 \% \mathrm{CO}_{2}$ incubator at $37^{\circ} \mathrm{C}$. Living and dead cells were counted using Trypan blue dye, and FAM-LEHD-AOMK delivery efficiency was determined using a fluorescence microscope (FITC filter, 40x). The highest efficiency was obtained when the probes and the cells were incubated for $5 \mathrm{~min}$ in the presence of $10 \mu \mathrm{g} / \mathrm{mL}$ digitonin in 50\% RPMI hypotonic buffer.

\section{TRAIL or etoposide stimulation of Jurkat T cells in the presence of ABPs}

Jurkat T cells $\left(10^{5}\right)$ in 50\% RPMI hypotonic medium were seeded into 96 -well clear bottom plates $(50 \mu \mathrm{L} /$ well $)$ and immediately incubated with a panel of biotin-labeled probes 
$(25 \mu \mathrm{M})$ in the presence of $10 \mu \mathrm{g} / \mathrm{mL}$ of digitonin for $5 \mathrm{~min}$. Then $150 \mu \mathrm{L}$ of RPMI was added to the wells, and the plates were centrifuged at $500 \times g$ for $5 \mathrm{~min}$. The supernatants were then aspirated using an 8-channel vacuum device, and the cells were re-suspended into $100 \mu \mathrm{L}$ fresh media and allowed to recover for $2 \mathrm{~h}$. Cells were stimulated with TRAIL $(100 \mathrm{ng} / \mathrm{mL})$ or etoposide $(25 \mu \mathrm{M})$ for $24 \mathrm{~h}$, and cell viability was determined using MTS assay, according to the manufacturer's protocol (CellTiter $96^{\circ}$ Aqueous One Solution Cell Proliferation Assay, G3582, Promega). The number of living cells was reported as a survival ratio, calculated based on the number of unstimulated control cells.

\section{TRAIL stimulation of Jurkat T cells in the presence of ABPs}

Jurkat T cells $\left(10^{5}\right)$ were seeded into two 96-well clear bottom plates (plate A and plate B, $80 \mu \mathrm{L} /$ well) and incubated with a panel of biotin-labeled probes $(25 \mu \mathrm{M}, 20 \mu \mathrm{L})$ for $4 \mathrm{~h}$. Then, ABPs from plate A were removed via centrifugation, and the cells were re-suspended into $100 \mu \mathrm{L}$ fresh media. Next, cells from both plates (plate A and plate B) were stimulated with TRAIL (100 $\mathrm{ng} / \mathrm{mL})$ for $24 \mathrm{~h}$, and cell viability was determined using an MTS assay, as described above.

\section{TRAIL/birinapant stimulation of MDA-MB-231 cells in the presence of ABPs}

MDA-MB-231 cells $\left(10^{4}\right)$ were seeded into two 96-well clear bottom plates (plate A, and plate B, $80 \mu \mathrm{L} /$ well) and incubated with a panel of biotin-labeled probes $(25 \mu \mathrm{M}, 20$ $\mu \mathrm{L})$ for $4 \mathrm{~h}$. Then, ABPs from plate A were removed via centrifugation, and the cells were re-suspended into $100 \mu \mathrm{L}$ fresh media. Next, cells from both plates (plate A and plate B) were stimulated with TRAIL $(100 \mathrm{ng} / \mathrm{mL})$ plus a smac mimetic, birinapant $(2 \mu \mathrm{M})$ for $24 \mathrm{~h}$, and cell viability was determined using an MTS assay, as described above.

\section{Caspase-3 and caspase-9 inhibition profiles}

Recombinant caspase-3 $(10 \mathrm{nM})$ and caspase-9 $(10 \mathrm{nM})$ were pre-activated in optimal caspase buffer for $15 \mathrm{~min}$ at $37^{\circ} \mathrm{C}$ and then incubated with 13 different inhibitors (at $0.01,0.1$, 1 , and $10 \mu \mathrm{M})$ in 96 -well plates for $30 \mathrm{~min}$ at $37^{\circ} \mathrm{C}$. A preferred substrate (Ac-DEVD-ACC for caspase-3 or AcLEHD-ACC for caspase-9) was then added, and the reaction progress was monitored using CLARIOstar plate reader (BMG Labtech), operating in the fluorescence kinetic mode ( $355 \mathrm{~nm}$ excitation, $460 \mathrm{~nm}$ emission, gain 650) using 96well plates (Corning, NY, USA). Percent caspase inhibition was calculated, and the results were represented as heatmaps.

\section{Assay of the Jurkat $T$ cell cytosolic extracts}

Hypotonic lysis of the Jurkat $\mathrm{T}$ cells was performed and the cytosolic fraction was collected, as described [32]. The total protein concentration in the lysate was $8 \mathrm{mg} / \mathrm{mL}$. Samples were stored at $-80^{\circ} \mathrm{C}$ until use, when $100 \mu \mathrm{L}$ aliquots were thawed to room temperature and preincubated for $5 \mathrm{~min}$ with $10 \mu \mathrm{M}$ of various inhibitors. The extract was then activated by the addition of dATP and horse cytochrome $\mathrm{c}$ in the presence of a proteasome inhibitor, as described [13]. Caspase-3 activation was monitored using $100 \mu \mathrm{M}$ AcDEVD-ACC substrate. In parallel, Jurkat cell extracts were preincubated for $5 \mathrm{~min}$ with $10 \mu \mathrm{M}$ of various inhibitors and activated with dATP/cytochrome $\mathrm{c}$ for $30 \mathrm{~min}$. The samples were then resolved on SDS-PAGE, and caspase-3 and -9 were detected by immunoblotting, as described above.

Acknowledgements This project received funding from the European Union's Horizon 2020 research and innovation program under the Marie Skłodowska-Curie grant agreement No. 661187 (to MP), and was supported by the National Science Centre grant 2011/03/B/ST5/ 01048 in Poland (to MD) and NIH grant R01 GM099040 to (GSS).

\section{Compliance with ethical standards}

Conflict of interest The authors declare that they have no conflict of interest.

\section{References}

1. Taylor RC, Cullen SP, Martin SJ. Apoptosis: controlled demolition at the cellular level. Nat Rev Mol Cell Biol. 2008;9:231-41.

2. Reed JC. Apoptosis-based therapies. Nat Rev Drug Discov. 2002;1:111-21.

3. Denault JB, Salvesen GS. Caspases: keys in the ignition of cell death. Chem Rev. 2002;102:4489-4500.

4. Thornberry NA, Rano TA, Peterson EP, Rasper DM, Timkey T, Garcia-Calvo M, et al. A combinatorial approach defines specificities of members of the caspase family and granzyme B. Functional relationships established for key mediators of apoptosis. J Biol Chem. 1997;272:17907-11.

5. Bouchier-Hayes L, Green DR. Caspase-2: the orphan caspase. Cell Death Differ. 2012;19:51-57.

6. Verhagen AM, Coulson EJ, Vaux DL. Inhibitor of apoptosis proteins and their relatives: IAPs and other BIRPs. Genome Biol. 2001;2:REVIEWS3009.

7. Du C, Fang M, Li Y, Li L, Wang X. Smac, a mitochondrial protein that promotes cytochrome c-dependent caspase activation by eliminating IAP inhibition. Cell. 2000;102:33-42.

8. Saraste A, Pulkki K. Morphologic and biochemical hallmarks of apoptosis. Cardiovasc Res. 2000;45:528-37.

9. Shi J, Zhao Y, Wang K, Shi X, Wang Y, Huang H, et al. Cleavage of GSDMD by inflammatory caspases determines pyroptotic cell death. Nature. 2015;526:660-5.

10. Talanian RV, Quinlan C, Trautz S, Hackett MC, Mankovich JA, Banach D, et al. Substrate specificities of caspase family proteases. J Biol Chem. 1997;272:9677-82.

11. Poreba M, Szalek A, Kasperkiewicz P, Rut W, Salvesen GS, Drag M. Small molecule active site directed tools for studying human caspases. Chem Rev. 2015;115:12546-629. 
12. Poreba M, Strozyk A, Salvesen GS, Drag M. Caspase substrates and inhibitors. Cold Spring Harb Perspect Biol. 2013;5: a008680.

13. Poreba M, Kasperkiewicz P, Snipas SJ, Fasci D, Salvesen GS, Drag M. Unnatural amino acids increase sensitivity and provide for the design of highly selective caspase substrates. Cell Death Differ. 2014;21:1482-92.

14. Poreba M, Salvesen GS, Drag M. Synthesis of a HyCoSuL peptide substrate library to dissect protease substrate specificity. Nat Protoc. 2017;12:2189-214.

15. Edgington LE, Berger AB, Blum G, Albrow VE, Paulick MG, Lineberry $\mathrm{N}$, et al. Noninvasive optical imaging of apoptosis by caspase-targeted activity-based probes. Nat Med. 2009;15:967-73.

16. Vickers CJ, Gonzalez-Paez GE, Wolan DW. Selective detection of caspase-3 versus caspase-7 using activity-based probes with key unnatural amino acids. ACS Chem Biol. 2013;8:1558-66.

17. Liu Y, Patricelli MP, Cravatt BF. Activity-based protein profiling: the serine hydrolases. Proc Natl Acad Sci USA. 1999;96:14694-9.

18. Sieber SA, Niessen S, Hoover HS, Cravatt BF. Proteomic profiling of metalloprotease activities with cocktails of active-site probes. Nat Chem Biol. 2006;2:274-81.

19. Abuelyaman AS, Jackson DS, Hudig D, Woodard SL, Powers JC. Synthesis and kinetic studies of diphenyl 1-(N-peptidylamino) alkanephosphonate esters and their biotinylated derivatives as inhibitors of serine proteases and probes for lymphocyte granzymes. Arch Biochem Biophys. 1997;344:271-80.

20. Van Noorden CJ. The history of Z-VAD-FMK, a tool for understanding the significance of caspase inhibition. Acta Histochem. 2001;103:241-51.

21. McStay GP, Salvesen GS, Green DR. Overlapping cleavage motif selectivity of caspases: implications for analysis of apoptotic pathways. Cell Death Differ. 2008;15:322-31.

22. Berger AB, Sexton KB, Bogyo M. Commonly used caspase inhibitors designed based on substrate specificity profiles lack selectivity. Cell Res. 2006;16:961-3.

23. Pereira NA, Song Z. Some commonly used caspase substrates and inhibitors lack the specificity required to monitor individual caspase activity. Biochem Biophys Res Commun. 2008;377:873-7.

24. Berger AB, Witte MD, Denault JB, Sadaghiani AM, Sexton KM, Salvesen GS, et al. Identification of early intermediates of caspase activation using selective inhibitors and activity-based probes. Mol Cell. 2006;23:509-21.

25. Brady KD, Giegel DA, Grinnell C, Lunney E, Talanian RV, Wong W, et al. A catalytic mechanism for caspase-1 and for bimodal inhibition of caspase-1 by activated aspartic ketones. Bioorg Med Chem. 1999; 7:621-31.

26. Choe Y, Leonetti F, Greenbaum DC, Lecaille F, Bogyo M, Bromme D, et al. Substrate profiling of cysteine proteases using a combinatorial peptide library identifies functionally unique specificities. J Biol Chem. 2006;281:12824-32.

27. MacFarlane M. TRAIL-induced signalling and apoptosis. Toxicol Lett. 2003;139:89-97.

28. Wang S, El-Deiry WS. TRAIL and apoptosis induction by TNFfamily death receptors. Oncogene. 2003;22:8628-33.

29. Jang YJ, Park KS, Chung HY, Kim HI. Analysis of the phenotypes of Jurkat clones with different TRAIL-sensitivities. Cancer Lett. 2003;194:107-17.

30. Thomas WD, Hersey P. TNF-related apoptosis-inducing ligand (TRAIL) induces apoptosis in Fas ligand-resistant melanoma cells and mediates CD4 $\mathrm{T}$ cell killing of target cells. J Immunol. 1998;161:2195-2200.

31. Stennicke HR, Jurgensmeier JM, Shin H, Deveraux Q, Wolf BB, Yang $\mathrm{X}$, et al. Pro-caspase-3 is a major physiologic target of caspase-8. J Biol Chem. 1998;273:27084-90.
32. Denault JB, Eckelman BP, Shin H, Pop C, Salvesen GS. Caspase 3 attenuates XIAP (X-linked inhibitor of apoptosis protein)mediated inhibition of caspase 9. Biochem J. 2007;405:11-19.

33. Malladi S, Challa-Malladi M, Fearnhead HO, Bratton SB. The Apaf-1*procaspase-9 apoptosome complex functions as a proteolytic-based molecular timer. EMBO J. 2009;28:1916-25.

34. Scott FL, Denault JB, Riedl SJ, Shin H, Renatus M, Salvesen GS. XIAP inhibits caspase- 3 and -7 using two binding sites: evolutionarily conserved mechanism of IAPs. EMBO J. 2005;24:645-55.

35. Garcia-Calvo M, Peterson EP, Leiting B, Ruel R, Nicholson DW, Thornberry NA. Inhibition of human caspases by peptide-based and macromolecular inhibitors. J Biol Chem. 1998;273:32608-13.

36. Zhou Q, Snipas S, Orth K, Muzio M, Dixit VM, Salvesen GS. Target protease specificity of the viral serpin CrmA. Analysis of five caspases. J Biol Chem. 1997;272:7797-7800.

37. Medepalli K, Alphenaar BW, Keynton RS, Sethu P. A new technique for reversible permeabilization of live cells for intracellular delivery of quantum dots. Nanotechnology. 2013;24:205101.

38. Ryan CA, Stennicke HR, Nava VE, Burch JB, Hardwick JM, Salvesen GS. Inhibitor specificity of recombinant and endogenous caspase-9. Biochem J. 2002;366:595-601. (Pt 2)

39. Finlay D, Vamos M, Gonzalez-Lopez M, Ardecky RJ, Ganji SR, Yuan H, et al. Small-molecule IAP antagonists sensitize cancer cells to TRAIL-induced apoptosis: roles of XIAP and cIAPs. Mol Cancer Ther. 2014;13:5-15.

40. Callus BA, Vaux DL. Caspase inhibitors: viral, cellular and chemical. Cell Death Differ. 2007;14:73-78.

41. MacKenzie SH, Schipper JL, Clark AC. The potential for caspases in drug discovery. Curr Opin Drug Discov Devel. 2010;13:568-76.

42. Vickers CJ, Gonzalez-Paez GE, Umotoy JC, Cayanan-Garrett C, Brown SJ, Wolan DW. Small-molecule procaspase activators identified using fluorescence polarization. Chembiochem. 2013;14:1419-22.

43. Vickers CJ, Gonzalez-Paez GE, Litwin KM, Umotoy JC, Coutsias EA, Wolan DW. Selective inhibition of initiator versus executioner caspases using small peptides containing unnatural amino acids. ACS Chem Biol. 2014;9:2194-8.

44. Brady KD. Bimodal inhibition of caspase-1 by aryloxymethyl and acyloxymethyl ketones. Biochemistry. 1998;37:8508-15.

45. Sprick MR, Rieser E, Stahl H, Grosse-Wilde A, Weigand MA, Walczak H. Caspase-10 is recruited to and activated at the native TRAIL and CD95 death-inducing signalling complexes in a FADD-dependent manner but cannot functionally substitute caspase-8. EMBO J. 2002;21:4520-30.

46. Wang J, Chun HJ, Wong W, Spencer DM, Lenardo MJ. Caspase10 is an initiator caspase in death receptor signaling. Proc Natl Acad Sci USA. 2001;98:13884-8.

47. Fernald K, Kurokawa M. Evading apoptosis in cancer. Trends Cell Biol. 2013;23:620-33.

48. Vanden Berghe T, Kaiser WJ, Bertrand MJ, Vandenabeele P. Molecular crosstalk between apoptosis, necroptosis, and survival signaling. Mol Cell Oncol. 2015;2:e975093.

49. Tait SW, Ichim G, Green DR. Die another way--non-apoptotic mechanisms of cell death. J Cell Sci. 2014;127(Pt 10):2135-44.

50. Maly DJ, Leonetti F, Backes BJ, Dauber DS, Harris JL, Craik CS, et al. Expedient solid-phase synthesis of fluorogenic protease substrates using the 7-amino-4-carbamoylmethylcoumarin (ACC) fluorophore. J Org Chem. 2002;67:910-5.

51. Stennicke HR, Salvesen GS. Caspases: preparation and characterization. Methods. 1999;17:313-9.

52. Scaffidi C, Medema JP, Krammer PH, Peter ME. FLICE is predominantly expressed as two functionally active isoforms, caspase-8/a and caspase-8/b. J Biol Chem. 1997;272:26953-8. 
53. Poreba M, Solberg R, Rut W, Lunde NN, Kasperkiewicz P, Snipas SJ, et al. Counter selection substrate library strategy for developing specific protease substrates and probes. Cell Chem Biol. 2016;23:1023-35.

54. Bromme D, Nallaseth FS, Turk B. Production and activation of recombinant papain-like cysteine proteases. Methods. 2004;32:199-206.

55. Copeland RA. A practical introduction to structure, mechanism, and data analysis. In: Enzymes. 2nd ed. Hoboken, NJ: Wiley, 2000.

56. Poreba M, Szalek A, Kasperkiewicz P, Drag M. Positional scanning substrate combinatorial library (PS-SCL) approach to define caspase substrate specificity. Methods Mol Biol. 2014;1133:41-59.

57. Pop C, Salvesen, GS. J Biol Chem 2009;284:21777.

58. Chipuk JE, Moldoveanu T, Llambi F, Parsons MJ, Green DR. Mol Cell. 2010;37:299.
59. Salvesen GS, Riedl SJ. Cell Cycle. 2009;8:2723.

60. Schafer ZT, Kornbluth S. Dev Cell. 2006;10:549.

61. Lamkanfi M, Festjens N, Declercq W, Vanden Berghe T, Vandenabeele P. Cell Death Differ. 2007;14:44.

62. Scott FL, Denault JB, Riedl SJ, Shin H, Renatus M, Salvesen GS. EMBO J. 2005;24:645.

63. Garcia-Calvo M, Peterson EP, Leiting B, Ruel R, Nicholson DW, Thornberry NA. J Biol Chem. 1998;273:32608.

64. Zhou Q, Snipas S, Orth K, Muzio M, Dixit VM, Salvesen GS. J Biol Chem. 1997;272:7797.

65. Ferreira KS, Kreutz C, Macnelly S, Neubert K, Haber A, Bogyo M, Timmer J, Borner C. Apoptosis. 2012;17:503.

66. Fernandes-Alnemri T, Armstrong RC, Krebs J, Srinivasula SM, Wang L, Bullrich $F$ et al. Proc Natl Acad Sci U S A. 1996;93:7464.

67. Scaffidi C, Medema JP, Krammer PH, Peter ME. J Biol Chem. 1997;272:26953. 